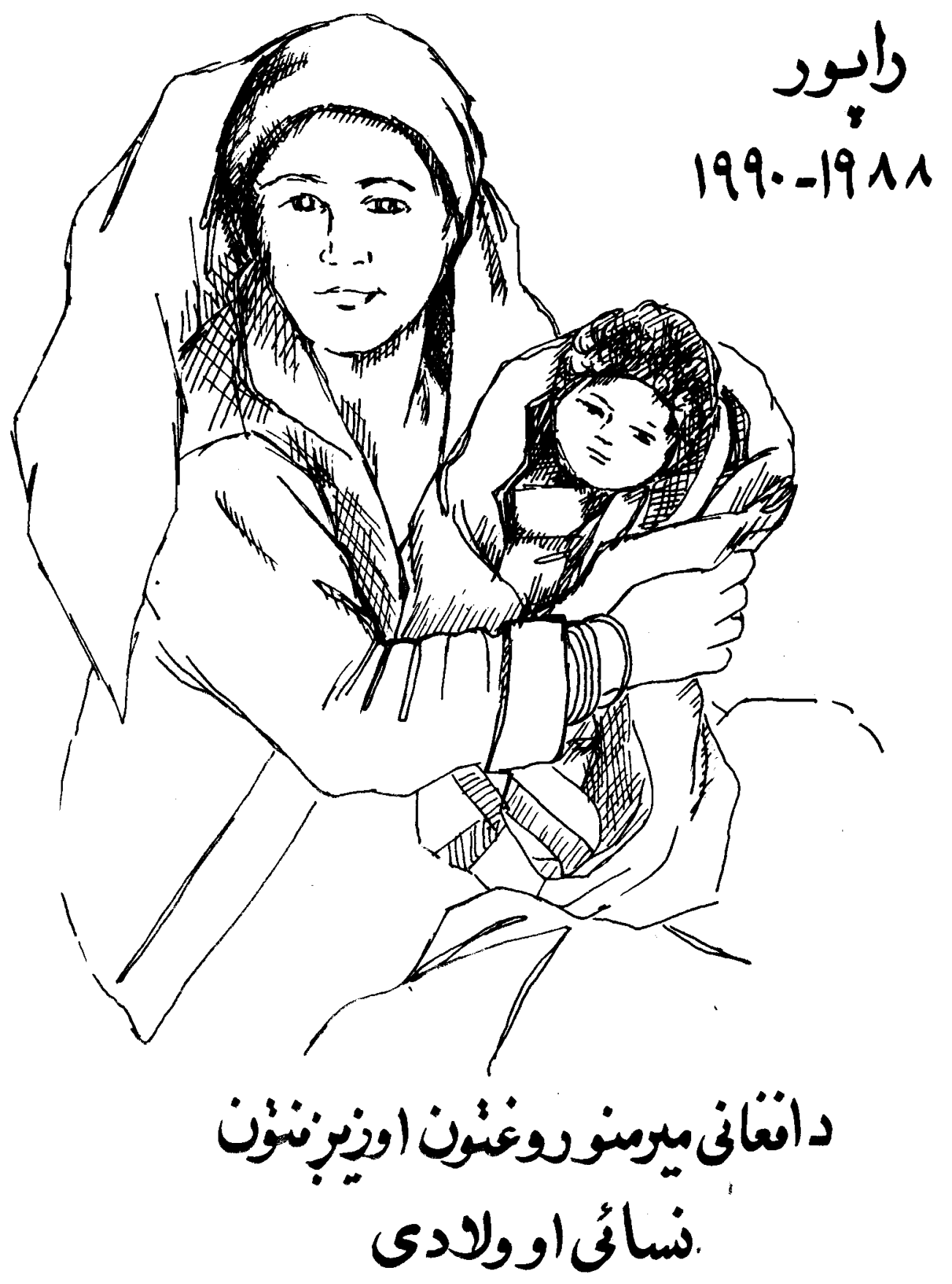

Report for 1988 - 90

Afghan Obs/Gyn Hospital 


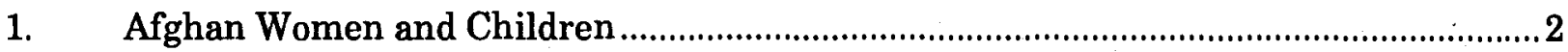

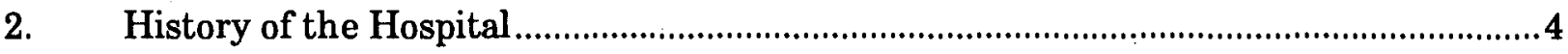

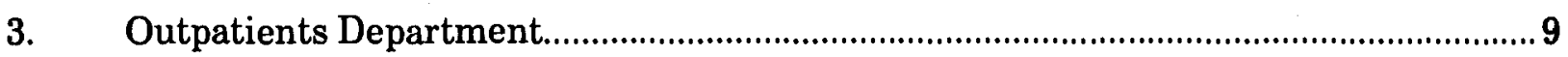

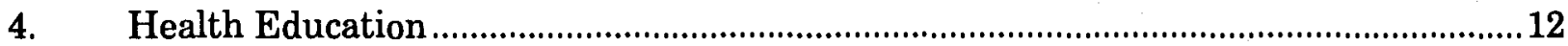

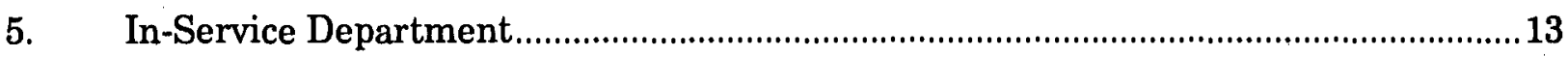

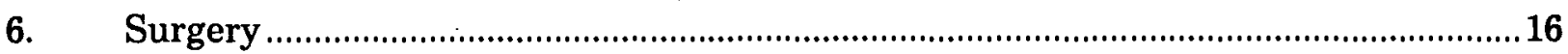

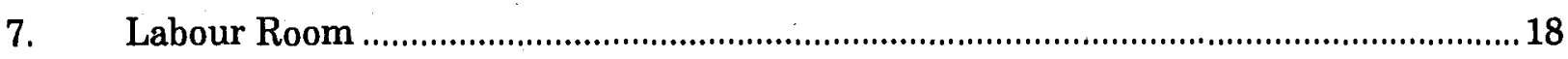

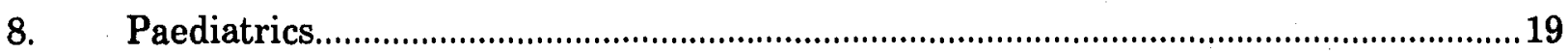

9. Other Departments

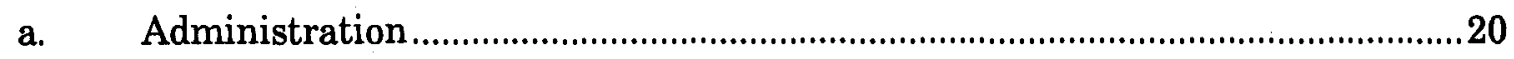

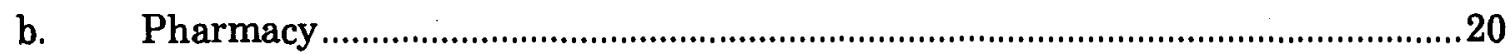

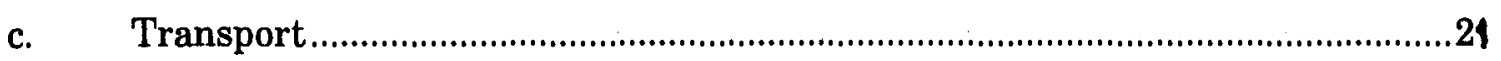

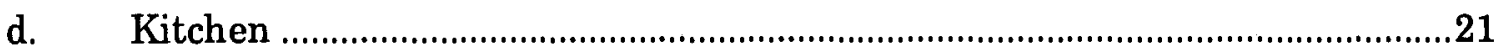

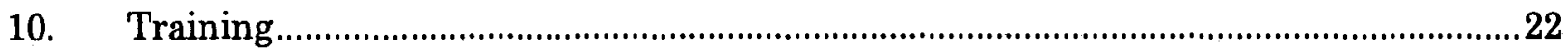

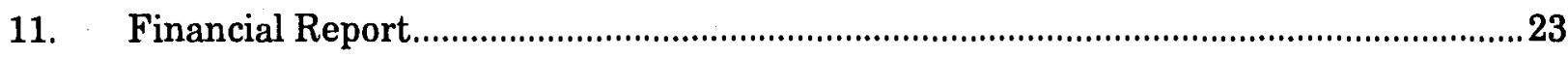

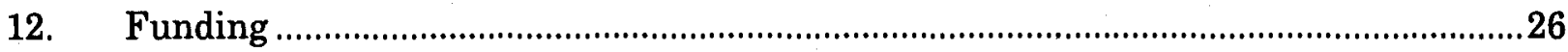

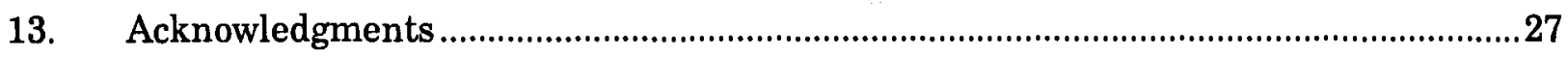

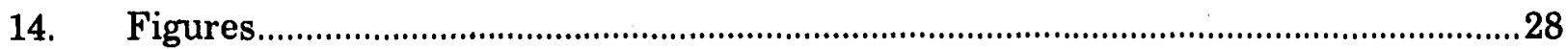

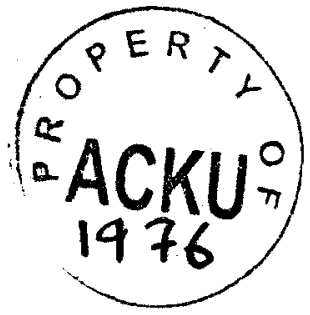




\section{Afghan Women and Children}

Since our country was invaded by the armies of the Soviet super power in 1979, more than 3 million Afghans have left their homes and fled over the border into Pakistan to seek refuge and peace. Despite the withdrawal of Soviet troops in 1989, refugees have continued to enter Pakistan as fighting continues between the Soviet-backed regime and the freedom fighters who now control a large section of our country. The Pakistani people and government have continued to extend their generous and compassionate welcome to their Afghan neighbours and without their assistance and protection the plight of the refugees would be much worse.

Since the first influx of refugees, international aid has flooded into Pakistan in an attempt to alleviate the suffering of these displaced people. However, since the Soviet withdrawal, many donor nations are questioning the need for further aid to the Afghan refugee population, despite the fact that continued fighting within Afghanistan prevents the majority from returning to their homes.

At least 65\% of Afghans living in Pakistan are women and children, but the world community has little concept of the conditions under which they live. Due to the restrictions placed upon them by society, particularly in view of the unnatural conditions under which they are now living, the voice of the female section of the population is very rarely heard and their needs only too often remain unmet.

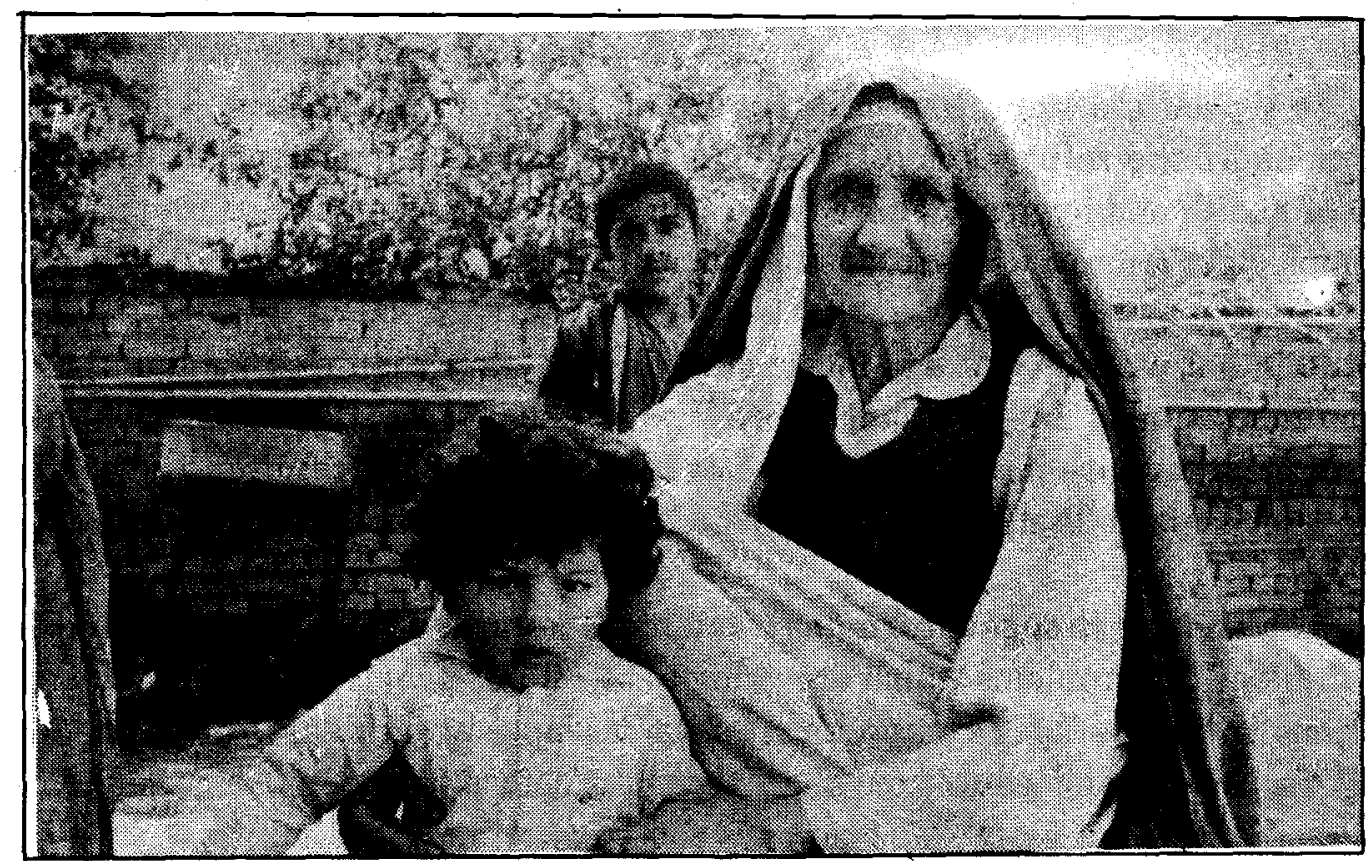

Since 1979, these women have been struggling to tend to their own needs and those of their families in an alien environment. Many of these women have lost loved ones in the Jihad (it is estimated that 1.2 million Afghans have been killed since fighting began) and a large 
number have had to take on full responsibility for their families while their husbands are away either looking for work or continuing the fight for freedom inside Afghanistan. In the course of the past 12 years. attempts to alleviate the specific problems of women and children have produced very little progress, and further efforts need to be concentrated in this direction.

It has been estimated that at any one time $40 \%$ of the female population aged between 16 and 45 years is pregnant. A survey carried out by IRC in 1986-7 in refugee camps in Hangu and Thal found a total marital fertility rate of 13.6 (the total marital fertility rate is equal to the hypothetical number of children a woman would have by the end of childbearing age, subject to the current set of age specific fertility rates), the next highest fertility rate registered by the WHO was 10.5 . The survey also showed an incidence of miscarriage/still birth of 23.5\% The child and maternal death rates in Afghanistan are the highest in the world and the life expectancy the lowest.

The circumstances under which the women live affects their physical and mental condition as well as the health of their unborn children. Pregnancy demands a balanced diet, which many women find difficult to achieve in their present situation. A large percentage of women suffer from anaemia and malnutrition due to their poor diet. For many their sole nutritional intake comes from bread, potatoes and rice, with meat being available only on an occasional basis. In most Afghan homes, the women are the last to eat, after the men and the children, and there is often insufficient food to go around. Hygiene standards in the refugee camps are frequently very poor and sanitation facilities are all too often inadequate. The standard of education amongst the refugees is generally very low and this applies particularly to their knowledge of health and hygiene. These factors, in addition to the crowded conditions in the refugee camps, have led to a widespread incidence of disease and infection.

Although the infant mortality rate in most camps is now lower than that inside Afghanistan, it remains unacceptably high. Infant mortality is usually due to diarrhoea, infection, malnutrition or premature birth. The rate of death amongst older children is also high and many others develop debilitating conditions which will affect them throughout their lives.

As time goes on and our thoughts turn more and more towards a return to our homeland, we must also think of the problems which are going to affect our people on their return. Despite the conditions in the refugee camps, many families now have access to better facilities, particularly for health and education, than they did before they left Afghanistan. Efforts must be directed from an early stage towards the creation of a viable infrastructure inside Afghanistan to cater to the needs of returning refugees. The particular needs of women and children must be given proper attention when plans are made or their unhappy situation will only be perpetuated. 
The proposal to establish the Afghan Obs and Gynae Hospital was originally formulated in 1983 by Dr M Hussain Momand, now Director of the Hospital and Dr Qudratullah Mojadidi, now a member of the hospital's Board of Directors. Dr Momand and Dr Mojadidi had become aware of the appalling state of neglect which existed with regard to the health of female refugees and wished to do something practical to address the problems of this particularly disadvantaged sector of the population. To this day, the Afghan Obs and Gynae Hospital remains the only hospital facility in the North West Frontier Province serving the obstetric and gynaecological needs of a population numbering approximately 700,000 women.

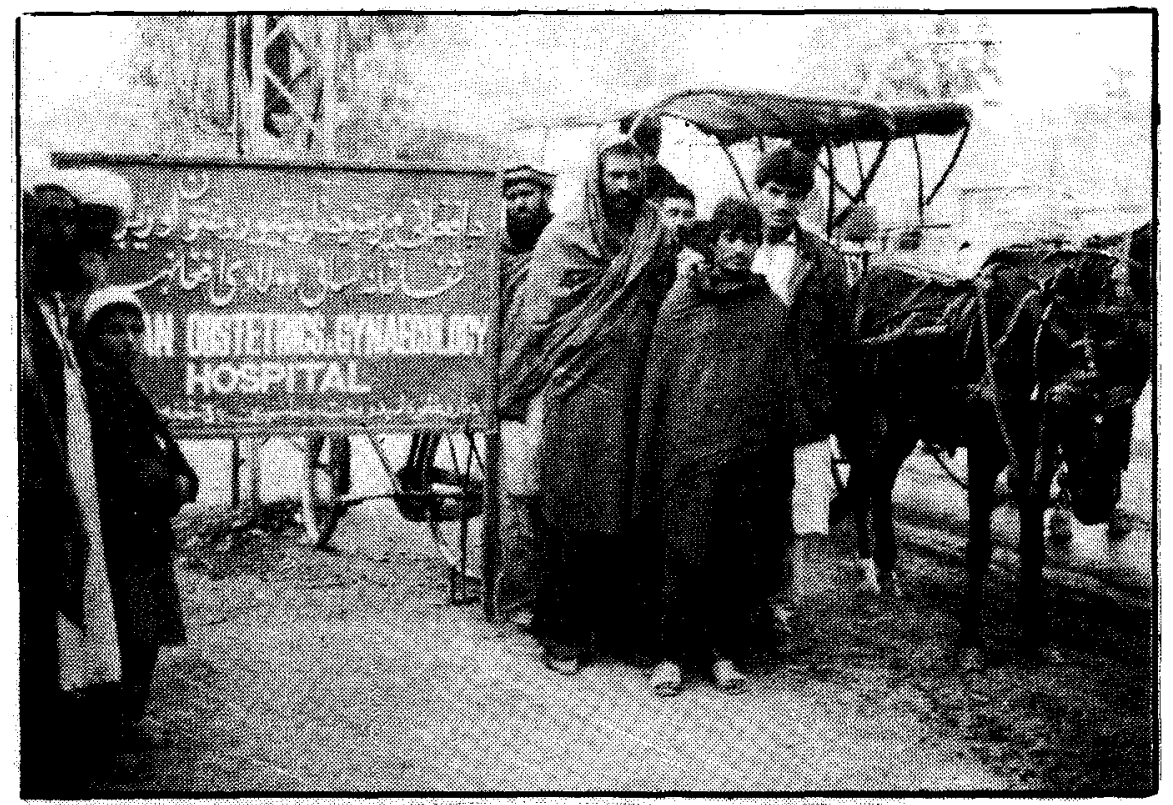

The proposal was submitted to various aid organisations and independent donors and the American Non-Governmental Organisation (NGO), International Rescue Committee (IRC) expressed an interest in the proposal - one of the first instances of an international aid organisation supporting a major proposal from an Afghan- led NGO. IRC gave their assent to the proposal early in 1984 and the hospital was established in November of that year. Further funding from American sources was secured through the efforts of Dr. Qudratullah Mojadidi.

From the beginning the hospital has offered its services to any woman in need of treatment; although the hospital was set up to treat Afghan women, we also treat any Pakistani women who present themselves to us. All treatment is offered completely free, this includes medical and nursing costs, in-service and operation costs, the cost of any laboratory tests, clinical supplies consumed and any medicines prescribed. If we are unable to treat a patient and have to refer her to another hospital we also cover any charges that hospital may make. We have recently estimated that the average annual treatment cost of each individual patient is approximately $\$ 19$. 
The hospital started life with 3 doctors; 1 male and 2 female, and 4 nurses. For the first 10 months, the facilities consisted solely of 3 examination rooms which were used to conduct outpatient clinics. Our experiences in the outpatient clinic enabled us to ascertain the types of conditions and patients we would be encountering. It is interesting to note that during the first 3 months of the Afghan Obs and Gynae Hospital's life, only 30 patients per month presented for treatment. This bears testimony to the extreme conservatism of the Afghan population and the importance they attach to preserving their family honour by the seclusion of the women. This inherent conservatism has been enhanced during war-time and the seclusion of women is even more strictly enforced among those living in exile. However, over time the hospital gained the trust of the community and our patient numbers began to rise dramatically.

At this time we were referring all our pregnant patients to other hospitals for delivery. As our rate of ante-natal attendances continued to increase, we soon realised that a delivery room and in-service area were essential. Further discussions were held with IRC, following which a 5 bed ward and labour room were constructed.

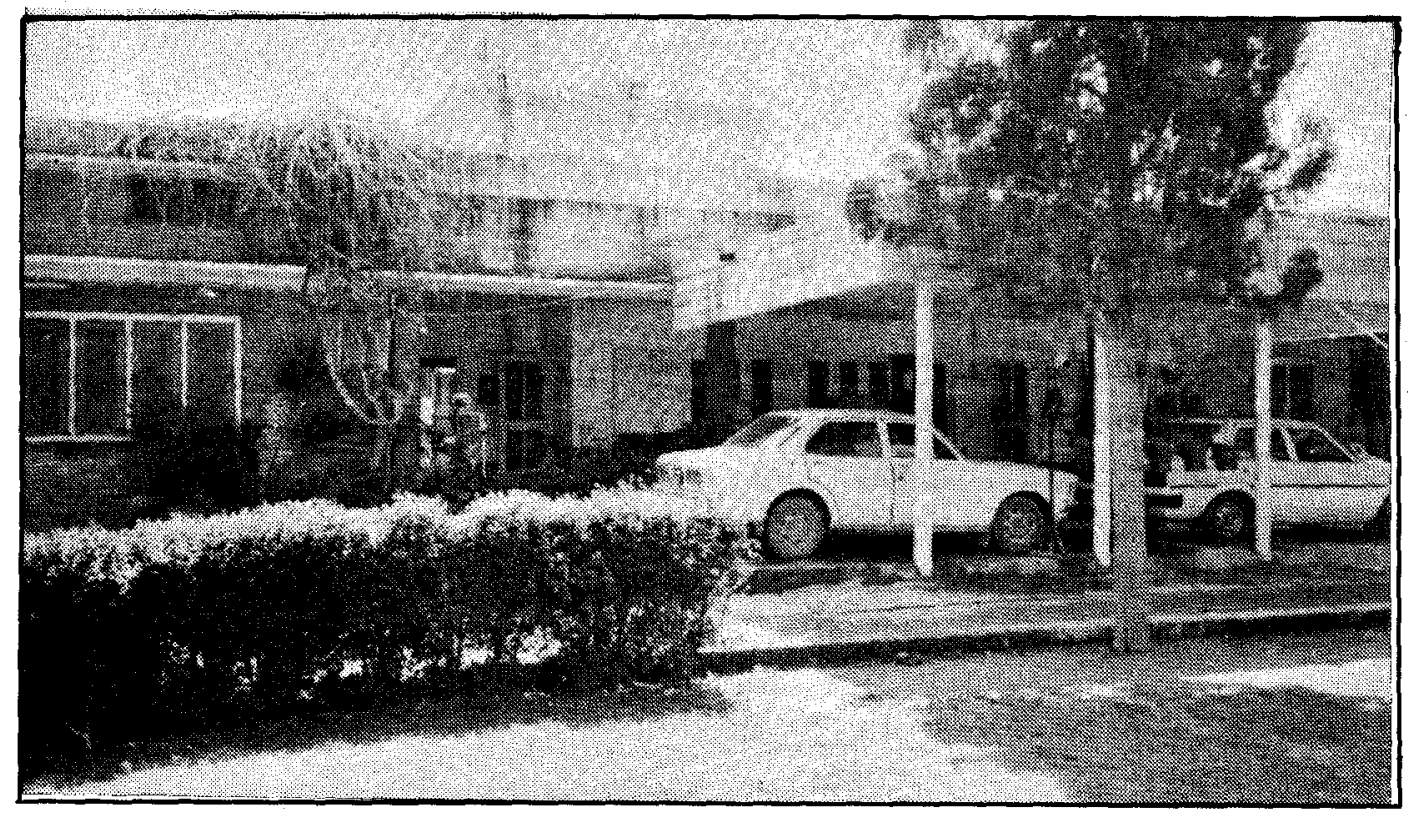

In March 1986 our surgical unit began functioning, enabling us to deal ourselves with some of the more complicated cases which had previously been referred to the nearby Pakistani Khyber Teaching Hospital. The theatre suite consists of an operating theatre, a recovery room and a sterilization and scrub room. Most of the equipment was purchased locally, whilat the instruments were donated by friends in America with the encouragement of Dr. Mojadidi and the operation table and emergency light were donated by Action Medicale of France. 
A new building for in-service patients was opened in February 1986. This consisted of 5 airconditioned wards each with 3 beds and a nursing station situated to allow observation of all patients. As demand for our services grew, the in-service area was expanded to accommodate 24 beds, in 8 three-bedded wards. We offer a 24 hour emergency service on a permanent basis, with a doctor and nurses always on duty and a full operating team on round the clock call. Here, as in the West, the majority of babies seem to be born at night. Thanks to the contribution of Dr. William Hazlett, a retired obstetrician from the United States, who has been with us since January 1988, we are now able to deal with most surgical cases ourselves, although certain cases are still referred to the Khyber Hospital.

A new outpatient block was added in 1988, and currently houses our outpatient clinics, the health education service, the vaccination area and the hospital pharmacy and some administrative accommodation. The Health Education Department (See Section 4) was opened in 1990 and provides our patients with advice on basic health practices and preventive care.

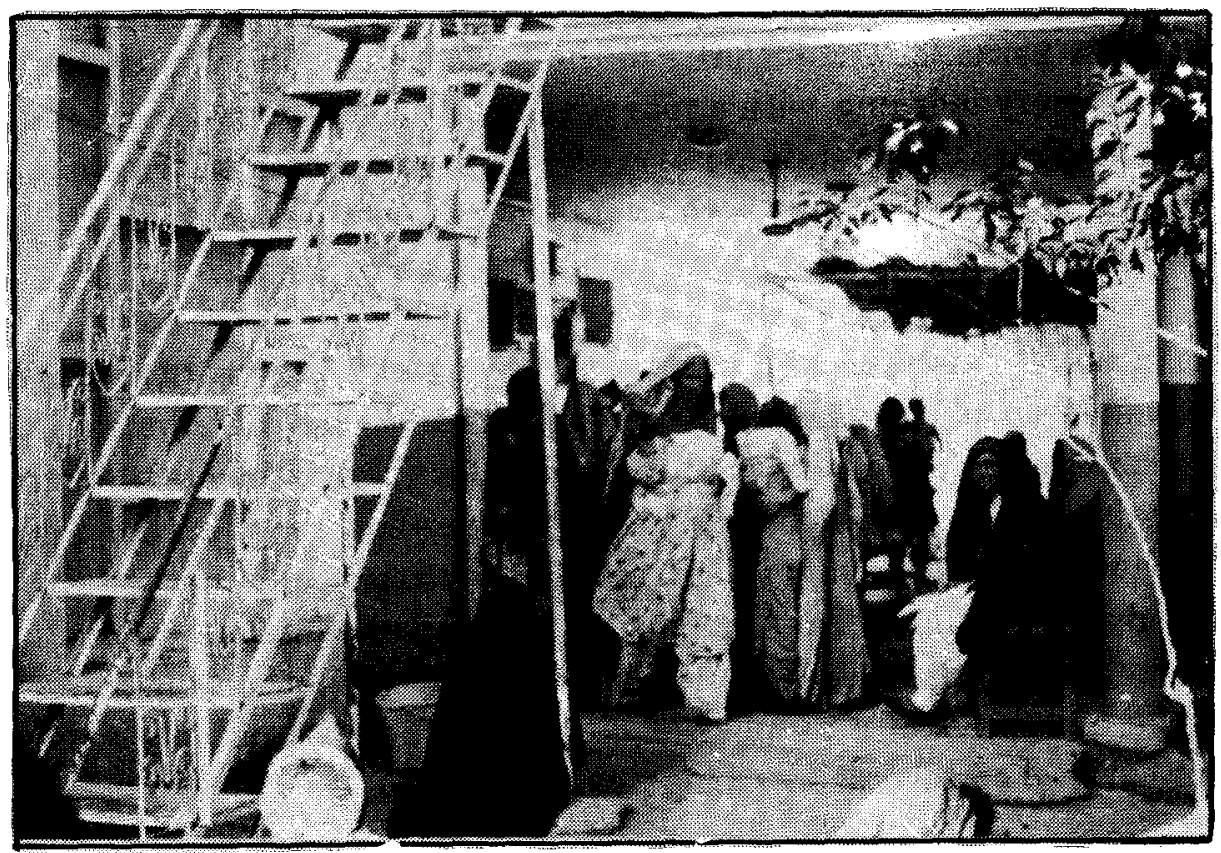

Our first vaccination programme began in 1986 and immunised 100 children and 30-40 women per week. This programme was halted in May 1987 and was replaced by a new programme under the supervision of the EPI (Expanded Programme for Immunisation) in July of that year. This programme was temporarily halted in June 1988 and restarted the following January. Although we have continued our vaccination programme we have, unfortunately, failed to achieve the coverage we had hoped.

From the very beginning, the Afghan Obs and Gynae Hospital has had two equally important and complementary aims - to treat Afghan women and to train Afghan medical personnel. To this latter end we have provided the practical component of training programmes organised by other organisations. We have enlisted the support of expatriate doct ors and nurses to give 
on the job training to our own staff and we are in the process of devising an extensive midwife training programme for Afghan nurses in conjunction with WHO (see Section 10).

We are currently planning an outreach programme in local refugee camps, in order to give the female population immediate access to ante-natal care, gynaecological treatment and health education. The programme will begin with the establishment of women's Basic Health Units (BHUs) in 3 local camps and if successful, will be expanded to cover a wider area.

Our workload has continued to grow over the past 3 years, we are now seeing approximately 2,000 outpatients a month, $60 \%$ of whom attend for ante-natal care. Our in-service department regularly treats over 400 patients per month, of whom about 300 are deliveries. It is encouraging to see that many women who are pregnant for the first time are now attending the hospital with the intention of delivering here.

We currently employ approximately 90 staff, including 12 doctors and 31 nurses to cater to the needs of these patients. The majority of the staff are employed in the outpatient clinics which take place every morning, with a rota of staff covering the in-service area on a 24 hour basis. The vast majority of our staff (84\%) are Afghan, something which we are very keen to encourage as one of our main aims is to train staff who will one day return to Afghanistan and practice and disseminate the skills we have passed on to them.

Our funding situation has remained precarious throughout the years. Our first benefactor, IRC, has remained an important donor although their direct contribution has been much reduced in recent years. The United States Agency for International Development (USAID) has been a major donor and currently makes a generous contribution towards our staff salaries. We have also received regular assistance from a number of European NGO's including Swedish Committee for Afghanistan, Norwegian Refugee Council / Church Aid, Help (Germany) and Help the Afghans Foundation (the Netherlands). Aid from private donors and the embassies of a number of different countries, notably Australia, has been crucial to our survival on several occasions (see Section 12).

As for the future, as you can see from the figures at the end of this report, the growth in patient numbers shows no sign of abating and the search for funding to cover our inevitably ever-increasing expenses will continue. We hope to move into new fields with the introduction of an outreach programme and the development of the midwife training programme, and are also seeking funding for these service developments.

We are also looking to the future in Afghanistan - our long-term goal remains to relocate the hospital to Nangrahar province as soon as circumstances allow, Dr Momand, Director of the hospital is a native of the Nangrahar region, where he is well-known and respected. We hope to be able to develop our teaching role through links with the Nangrahar University Hospital Modical School, of which Dr Momand is himself a graduate, and to operate in the primary 
health care field through health education, the training of traditional birth attendants and co-operation with the local network of basic health units. 


\section{Outpatients Department}

As patient numbers grew, it became increasingly difficult to meet the demand for services in our existing accommodation. Therefore, when in 1988 an opportunity arose to acquire the building and space adjacent to the hospital for an outpatient department, it came as an answer to our prayers. As well as the outpatient clinics, this area also houses the pharmacy, vaccination and health education areas and the accounts department.

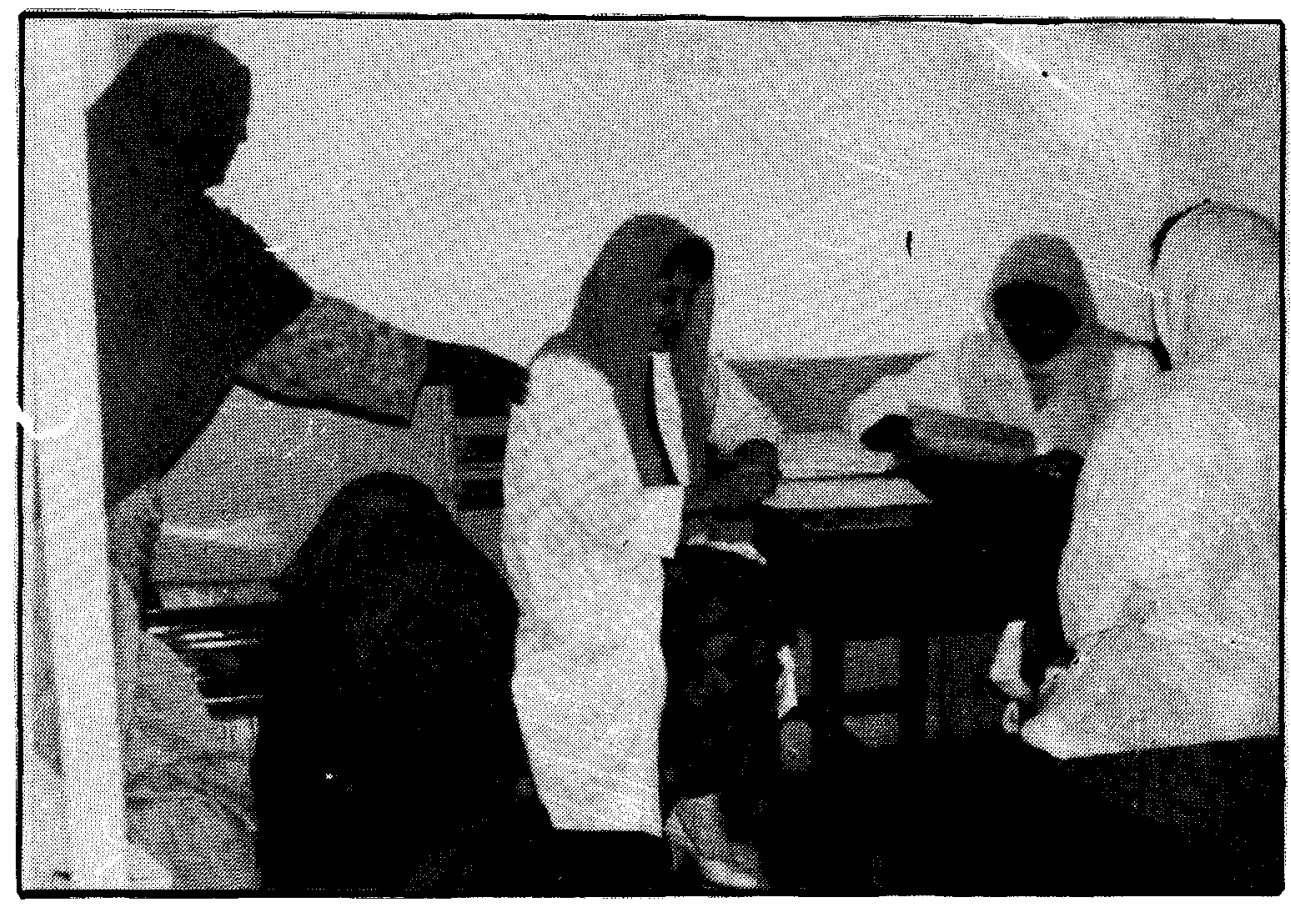

Clinics are held every day except Fridays and public holidays. Clinic starts at 8.30 am, although many patients arrive much earlier, and continues until all patients have been seen, usually at about $1 \mathrm{pm}$. On arrival each patient is given a numbered card which determines the order in which they are seen. Patients are first seen by a nurse, who prepares a permanent record card for them and ascertains whether they are an ante-natal or a gynaecology patient. Patients who are neither pregnant nor suffering from a gynaecological complaint are seen and given treatment if available, if not they are referred to an appropriate hospital.

The majority of patients come from the refugee camps in and around Peshawar; Katchgarie, Board, Naserbagh, Khazana, Khorason and Badaber, although a significant minority come from further afield - some have even arrived from as far away as Quetta, Karachi, the Punjab and from inside Afghanistan itself.

The number of patients seen daily increased steadily from $60-80$ in 1987 to about 120 in 1990. This is obviously reflected in the annual total number of patients seen which has almost doubled since 1987, increasing from 10,881 patients in that year to 21, 304 in 1990 (see Figures 1 and 2). The percentage of these women who attended for ante-natal care 
dropped from $60 \%$ in 1987 to $53 \%$ in 1989 but increased to $62 \%$ again in 1990 (see Figures 3 5).

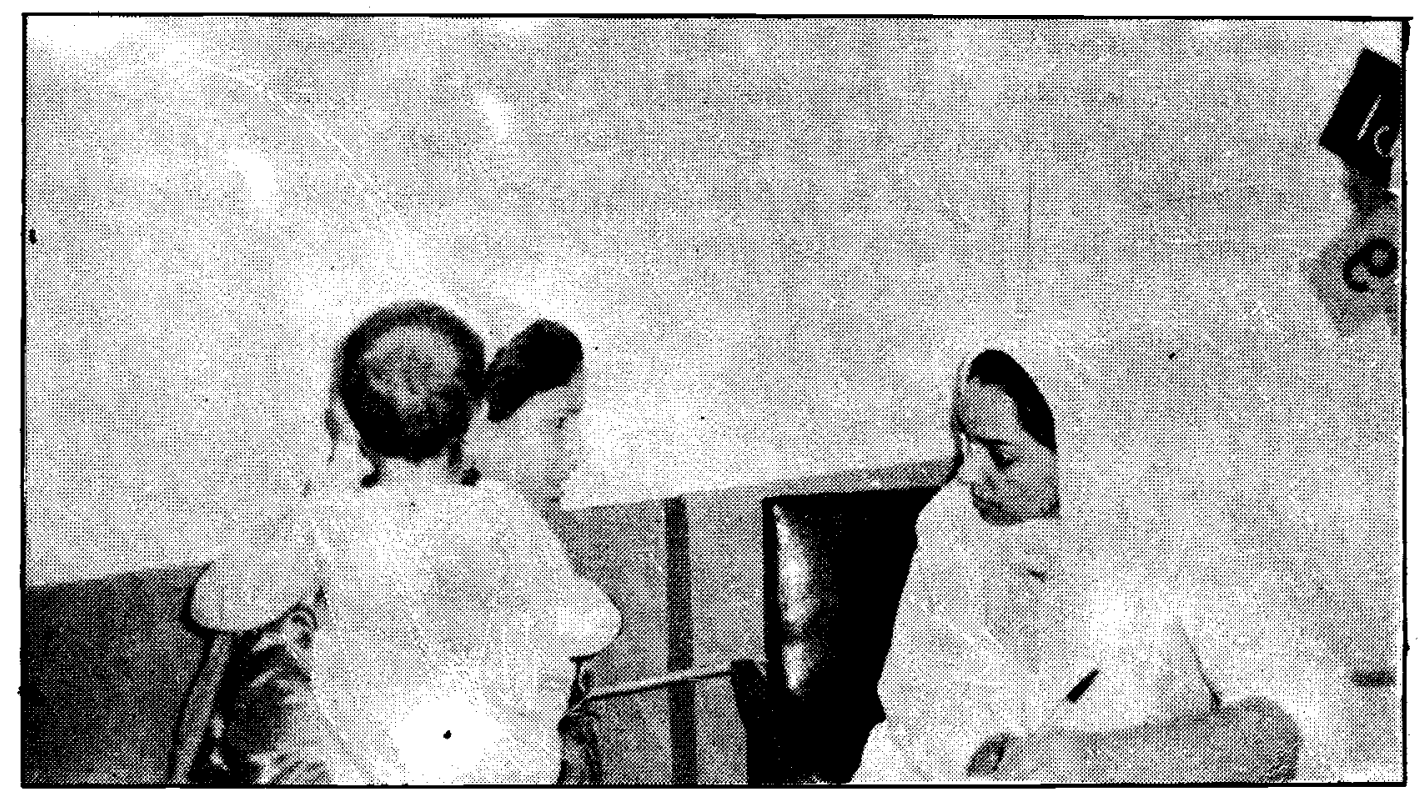

We welcome the opportunity to educate these women about labour and delivery, immunise them against tetanus and foresee any potential problems. Nearly all of them are anaemic to some extent and many have thyroid deficiency, malaria, tuberculosis, diarrhoea, intestinal parasites and other conditions resulting from the difficult circumstances in which they live. Some of the women are referred to the Afghan Obs and Gynae Hospital by Basic Health Units in the refugee camps or the Mercy Fund Mobile Obs and Gynae clinic, others hear about our services through relatives and neighbours who have attended the hospital in the past.

A further 6-7\% of our patients present with various obstetric complications, mainly miscarriages. Approximately 20\% of the women have gynaecological disorders, mainly involving menstrual problems for which we offer treatment and surgery when necessary.

$7-8 \%$ of the women (which represented over 1,400 in 1990) request family planning services. We believe that this service will be of increasing importance in the future, particularly as Afghan women have a very high fertility rate and marry very young, which means that they produce more children than any other group in the world (IRC survey). We had hoped to begin a specific Family Spacing Programme in August 1990, which would have involved creating a data base on fertility rates, etc for use by other interested agencies, as well as extending our birth spacing programme. Unfortunately, the promised funding from UNWPF has not become available and this project has had to he shelved for the present. 
We have only limited laboratory facilities at the hospital, which enable us to carry out only simple $\mathrm{Hb}$ determinations and routine urine and pregnancy tests; other laboratory tests and specimens are sent out for analysis to local laboratories.

Our vaccination programme (see figure 6), is conducted under the auspices of the Expanded Programme for Immunisation. The vaccines are administered by a trained vaccinator. We aim to vaccinate all babies born in the hospital, our pregnant mothers and other babies brought to the hospital by their mothers. The mothers are vaccinated against tetanus and the children against the six major killer diseases of childhood. 


\section{Health Education}

Our health education programme was started in March 1990 with the help of Refugee International of Japan, who kindly donated US $\$ 5,000$. The programme is run by a Health Education Co-ordinator and two Health Educators, who have completed the IRC health education training programme.

Providing health education to Afghan women is of paramount importance in improving their health status. The illiteracy rate among Afghan women is estimated to be 97-99\% - the highest in the world - and worldwide studies have proved that there is a strong correlation between literacy standards and maternal and infant mortality. Most of our patients are illiterate women who live in purdah with only very limited opportunities to move outside their homes. Their visits to the Afghan Obs and Gynae Hospital are one of the few opportunities open to them to receive information on a variety of health education topics, information which they can put into practice in the rearing of their families.

Our programme aims to give our patients and the female relatives who accompany them to the hospital a basic grounding in health practices and preventive care. This includes advice on sanitation, food preparation, nutrition, weaning, the importance of ORS (oral rehydration solution) in the treatment of diarrhoea, and birth spacing. We also offer a special short course in mine awareness, which is run in conjunction with Operation Salaam. 
The in-service area now consists of 6 rooms each containing three beds plus a 5 bed labour ward and a recovery room ( 24 beds in all). The nursing station allows the nursing staff to keep the patients permanently in view. 1 doctor and 3 post-graduate nurses are on duty in the in-service area at all times and a surgical team, supervised by Dr Hazlett, is on call 24 hours a day.
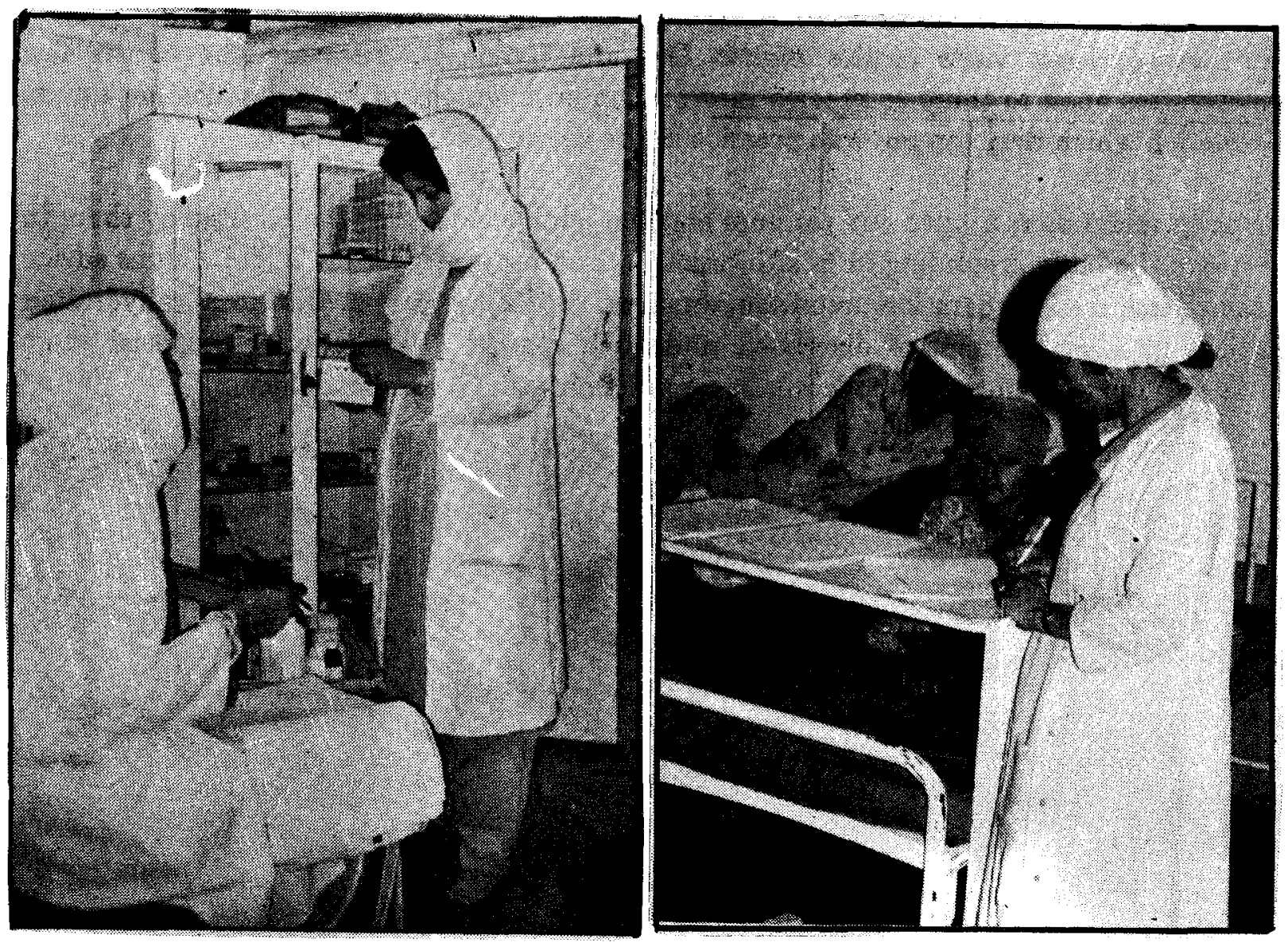

The number of patients attending the in-service area also continued to increase dramatically - from an average of 215 admissions per month in 1988 to an average of 394 in 1990 . Of these about $70 \%$ are deliveries and a further $20 \%$ are other obstetric cases (see Figures 1 and 7 ).

Many of the wromen present with complications of labour such as malpresentation, multiple pregnancies, placenta praevia and abruptio placenta. These conditions would most probably have resulted in fetal and/or maternal death had the woman not sought professional help. 
We are also faced with complications from deliveries in the camps such as post partum haemorrhage, sepsis etc, which are also potentially life-threatening conditions. A further group of women present post miscarriage, these women often require a dilation and curettage (D\&C).

The majority of women have a normal delivery and return home after 8-24 hours. Primagravid women (those who are having their first child) usually remain in the hospital a little longer. The women's chances of developing obstetric complications are enhanced by the underlying health problems many experience such as malnutrition, anaemia, tuberculosis and the general fatigue and stress of their daily lives in the camps.

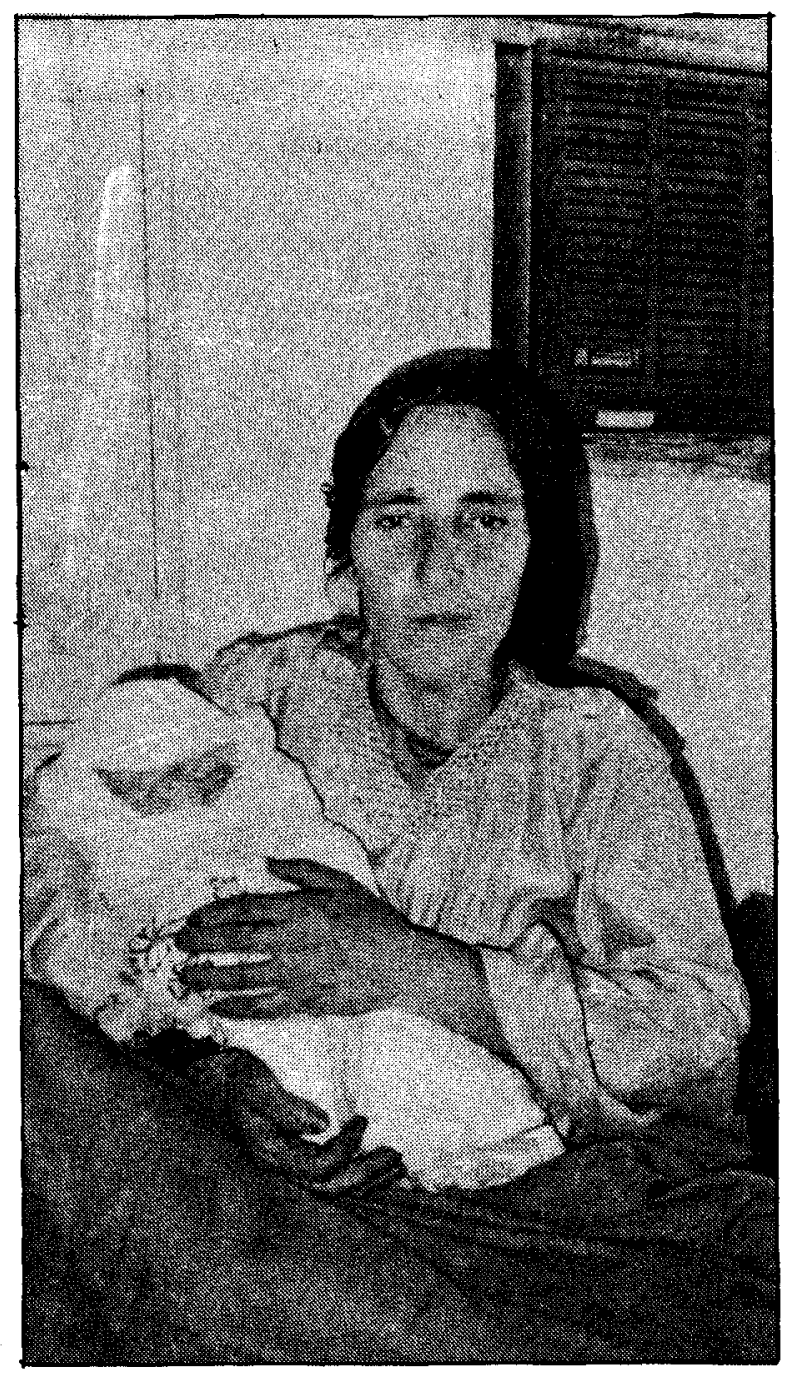

The majority of gynaecological patients admitted to the in-service area are those requiring surgery of some sort, for example a woman with dysfunctional uterine bleeding requiring a D\&C. More major cases include women with uterine prolapse, caused by multiple childbirth - these women often require a vaginal hysterectomy. Some women are also admitted for a tubal ligation, which is often carried out in conjunction with a Caesarian section.

All admissions, whether obstetric or gynaecological, have their blood analysed to determine their blood group, rhesus factor and haemoglobin level. Their urine is also tested for infection. All pre-operative patients require a chest $\mathrm{x}$-ray, electrocardiograph and general check-up by a physician. Blood for emergency transfusion is obtained from the local blood bank or donated by family members.

Our incillence of post-operative infection is very low due, we believe, to our surgical schedule which allows for 4 elective surgical cases week. This almost completely eliminates the risk of cross-infection on the ward

In many cases much needed surgery has to be delayed due to the patient's general physical condition or the presence of another condition such as anaemia, malaria or tuberculosis. In 
the majority of cases the woman's relatives are willing to sign the operation consent form, but in some cases they refuse and the woman returns home to undergo continued suffering or even death.

When a case arises which we are unable to treat ourselves, the Afghan Obs and Gynae Hospital arranges for the patient to be transferred to a local hospital, usually the Khyber Teaching Hospital or the Lady Reading Hospital and bears all the costs of hospitalisation.

In the summer of 1989 we were lucky enough to receive an ultrasound machine kindly donated by the Japanese Government. JICA (the Japanese International Co-operation for Assistance) also sent technical assistance in the shape of short-term Japanese experts who worked with our doctors and taught them how to operate this machine. Our anaesthesiologist is currently responsible for conducting these examinations. The ultrasound has been of tremendous benefit in diagnosing potential complications and has saved the lives of many infants and mothers since its installation in the hospital. 
The operating suite consists of a scrub room, a recovery room and a theatre. There is also an area set aside for minor procedures such asD\&Csand biopsies which do not require general anaesthesia. The major procedures are carried out by three senior doctors on a rotational basis, assisted by a junior doctor who is also being taught surgical techniques. All operations are supervised by Dr Hazlett, our resident consultant from the United States. One member of the medical staff has been trained in anaesthesia (a second is currently being trained at the Khyber Teaching Hospital and will rejoin our staff in April 1991), she is assisted by two nurses who have received some training at the hospital. The surgeons are also assisted by a trained theatre nurse and a junior nurse.

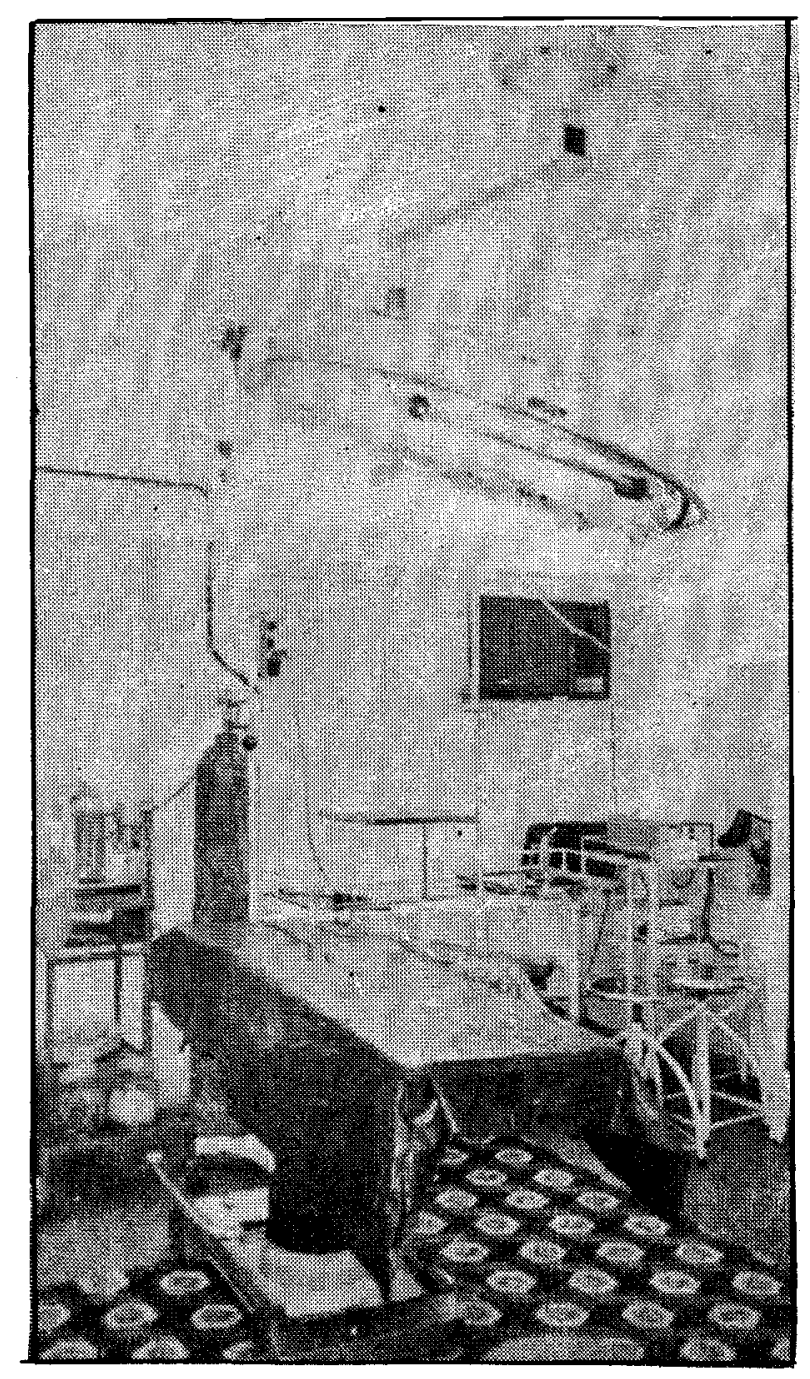

The number of major operations performed has remained fairly constant at just over 100 per year - the monthly total ranging from 5 to 23 operations in 1990 . However, the number of minor procedures carried out has risen dramatically over the past three years from 253 in 1988 to 570 in 1990 (See Figure 8). Dilations and curettage are quick to perform, relatively painless for the patient and provide an appropriate solution to many gynaecological problems.

50-60\% of all major procedures are Caesarian sections for a number of reasons, including fetal distress, failure to progress, malpresentation, etc. (see figures 9-11). The majority of these cases are emergencies. Of gynaecological cases, almost half are hysterectomies, both vaginal and abdominal, mostly performed as a result of such conditions as fibroid uterus and uterine prolapse. The majority of minor surgical procedures (over 60\%, see Figures 12-14) are carried out following miscarriages, the next most common cause is dysfunctional uterine bleeding. Such procedures are also performed in cases of infertility, fibroid uterus and retained placenta.

Women requiring minor surgery usually remain in hospital for only a few hours, while those who have undergone a major procedure may remain under observation for as long as a week 
to ten days. We are proud of low incidence of post-operative infection, which we believe is due to the strict control we exercise over sterilisation techniques for instruments and clothing. Our surgical schedule also means that we have a very low incidence of crossinfection within the in-service area. 


\section{Labour Room}

The labour room contains two delivery beds and one paediatric resuscitation table equipped with electric suction and oxygen. A qualified midwife and a nurse assistant, both of whom are capable of performing deliveries, are on duty at all times.

In 1990 we performed an average of 286 deliveries per month, a $300 \%$ increase over the number performed only 4 years ago. Our record month for deliveries was December of 1990 when 398 babies were born, which amounts to almost 13 per day (see Figures 11 - 13).

Each delivery is conducted under strict sterile conditions so as to minimise the possibility of post-partum infection, a technique whose success has been proven by the fact that almost $80 \%$ of women delivering in the hospital remain free of complications when they return for their post-natal visit.

The women usually deliver in the supine or reclining position, although some prefer to deliver in the traditional squatting position which is theoretically more practical as it allows the baby's head to descend at a faster rate. Many of the women deliver very soon after their admission to the hospital, although primagravid women tend to be in labour for 12-36 hours. About $20 \%$ of primagravid women receive an episiotomy (a cut in the skin to allow more room for the head to be born), which is a very low percentage by western standards.

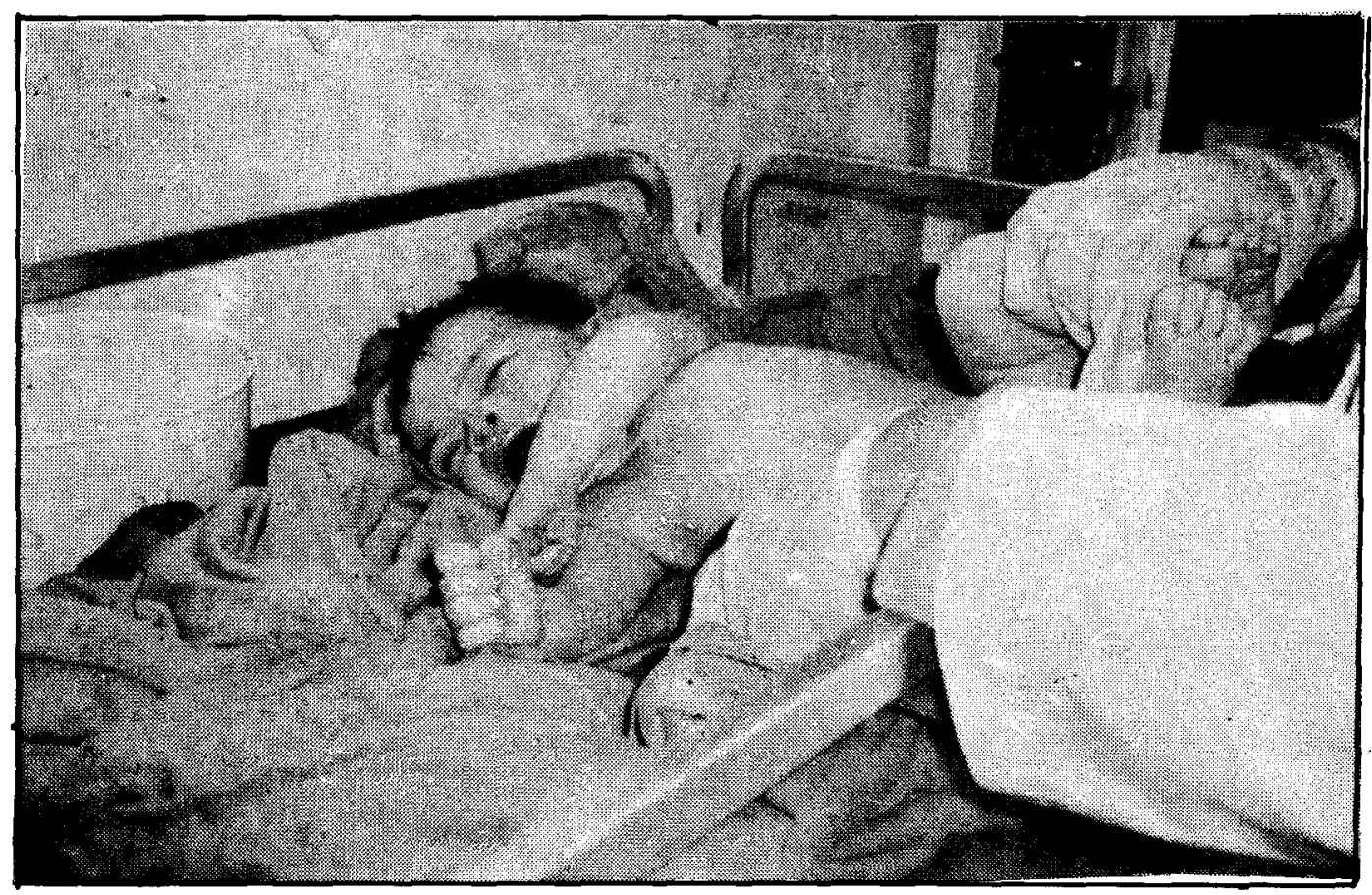

We have been very heartened to observe the increase in women attending the hospital for deliveries, particularly first time mothers for whom the risk of complications is greater. Although the majority of our women deliver normally, a significant number do develop sudden complications which, had they not been already in hospital, could have led to the death of the child or even the mother. 


\section{Paediatrics}

$20 \%$ of all births at the hospital are premature (before the 37th week of pregnancy). This high rate of prematurity is caused by anaemia, malnutrition, infection and multiple pregnancies, exacerbated by the stresses of camp life. Until recently we have had to refer all babies in need of specialised neonatal care to local hospitals which are sometimes reluctant to accept them either because their chances of survival are slim or because they were not born in that hospital and bedspace is not available for them.

We are now in the process of developing a neonatal unit, kindly funded by Help the Afghans Foundation, of the Netherlands. This unit is staffed by a resident paediatric fellow and two nurses and is supervised by an Afghan paediatrician. The unit cares for premature births, babies too weak to suckle, those with jaundice, suspected sepsis etc.

We are pleased that we finally have on the spot facilities to care for our sick babies but this is still an arta which needs to be worked at over the coming months so we can provide a truly comprehensive service for mothers and their babies 


\section{Other Departments}

a. Administration - The current administrative and management team consists of the physician-director, an accountant and a secretary who are all Afghan, and an expatriate deputy director (qualified as a physician's assistant) who is paid on a local salary. An expatriate administrator, who is paid a volunteer salary, joined us early in 1991. Further administrative assistance may be necessary to support the training and outreach programmes as they develop.

At the end of 1990, we received a donation from the Free Afghanistan Alliance of the United States which was used early in 1991 to purchase two personal computers which have already improved the quality and ease of preparation of our correspondence and documents. A patient recording system is currently being developed to ease the retrieval of patient files and to help in the compilation of statistics. We also hope to computerise our accounting systems during the coming months.

b. Pharmacy - The pharmacy is a central feature of the outpatient block. The pharmacist dispenses medicines free of charge to all outpatients and in-service patients as well as any staff who need treatment. If a patient is prescribed a drug which is not available in our pharmacy, they are directed to buy the medicine in the bazaar and the hospital will refund the cost. Most of the medicines we dispense are purchased locally, although some are kindly donated to us. Our outlay on medicines is very high, forming the second largest expenditure head after staff salaries.

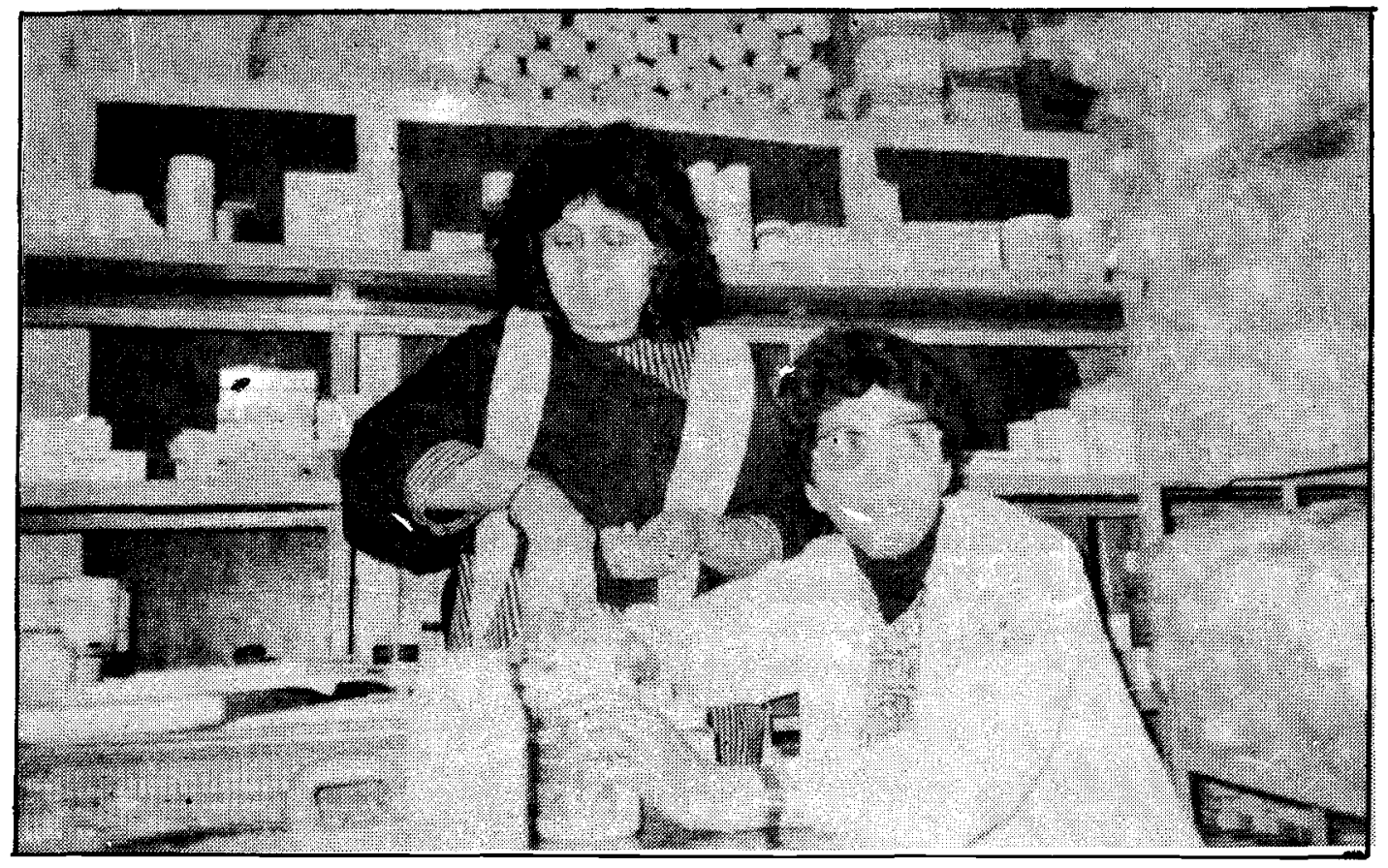


c. Transport - The current social and political climate in Peshawar places many restrictions on Afghan women and life is often difficult for those who choose to work outside the home. One way in which we can alleviate some of these difficulties is to provide transport to and from work for all our female staff (some 60 individuals). Our transport needs are therefore very great and are currently served by a 15 seater minibus and a 40 seater traditional Pakistani bus which is becoming a familiar sight around University Town. This latter vehicle was originally donated to the Commissionerate for Afghan Refugees by the Peoples' Republic of China and made available to us through IRC. We also have a small Suzuki van to transport supplies, a staff car and a 15 year old Toyota station wagon which has been converted into an ambulance. This vehicle has reached the end of its useful life and urgently needs replacement with a more reliable and appropriate vehicle.

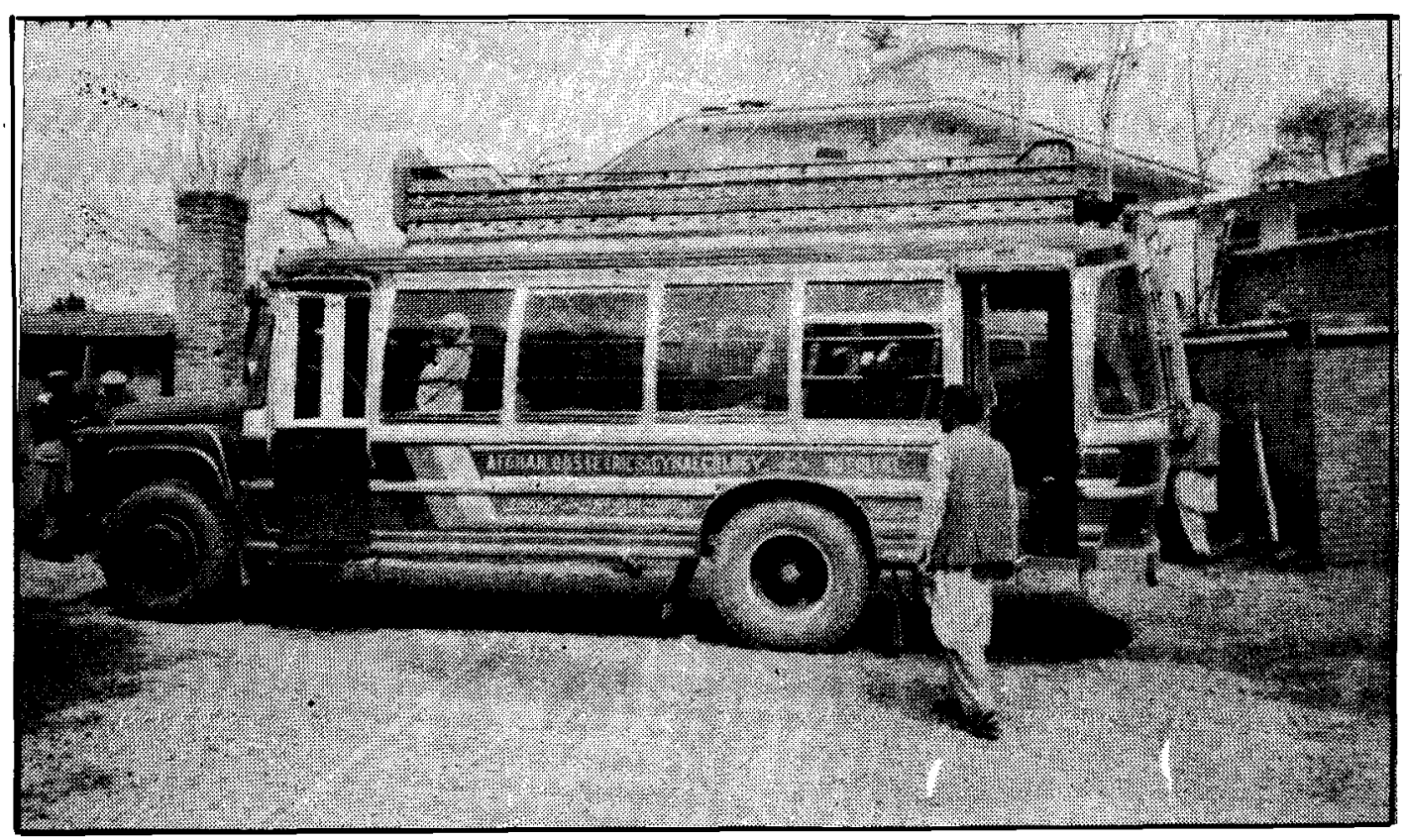

d. Kitchen - Our kitchen provides meals twice a day for all our staff and patients. Staff eat in a dining area while patients' meals are served in the ward area. The food is prepared by our team of a cook and 2 assistants. 


\section{Training}

The training role of the Afghan Obs and Gynae Hospital has always been as important as the patient care aspect. This training role takes a number of forms. Firstly the on-going on the job training of our medical and nursing staff through the input of expatriate specialists. We have been lucky enough over the past years to have had continued input from expatriate nurses and doctors from a number of different countries, particularly the United States. These expatriates have remained with us for periods ranging from 2 weeks to over 2 years and their input into training and staff development has been invaluable. At present we have working with us Dr William Hazlett, a retired obstetrician from the United States and Mrs Angelina Banmbuh, a nurse-midwife toutor from Cameroon, who has been with us for twelve months. We also welcome the input of Dr Mojadidi, who spends one month each year carrying out intensive training with our doctors.

Secondly, over recent years we have collaborated with a number of other local voluntary organisations and NGO's, providing practical training to support their theoretical training programmes. At present, we are training staff from the following organisations:

- $\quad$ Afghan Medical Aid - Training nurses

- Afghan Welfare Centre - Training female paramedics

- International Rescue Committee - Training midwife trainers

- $\quad$ Save the Children (UK) - Training midwife trainers

- IRC Women's Outreach Programme - Training health education staff

- Medical Sciences for Health - Refresher courses for female obstetricians/gynaecologists.

In the past few years we have also collaborated with the Union of Afghan Doctors and Freedom Medicine on training programmes for doctors. There are now doctors and nurses Working in 48 camps in North West Frontier Province, as well as in Afghanistan itself, who received some of their training at the Afghan Obs and Gynae Hospital.

Thirdly, we are currently working on the curriculum for a one year midwife training programme for trained nurses. Through this programme we hope to create a pool of trained midwives who can pass on their skills to other nurses both in Pakistan and in Afghanistan. The course will be run by Mrs Banmbuh, and hopefully a British volunteer midwife-trainer, with the help of a translator and will cover both theoretical and practical training in all aspects of midwifery and care of the newborn. We hope that this programme will be funded by the World Health Organisation. 
11. Financial Report

\section{Expenditure}

Medicine

782,388

Laboratory

340,371

Clinical Supply

192,907

227,025

256,461

Utilities (Electricity, Gas, Water, etc)

168,342

(Gasoline, Repair, Trans)

Construction

45,210

35,818

Dollars

34,017

14,799

8,387

9,871

11,150

7,319

Insurance (Staff, Vehicle,

36,852

1,965

Houses, Equipment)

Communisizion (Telephone,

1,557

Telegram, Postage)

Office Supply

76,115

1,602

Salary, Overtime, Bonus

$1,622,265$

3,309

5,276

70,533

Emergency Aid and Trips

Housing (house rent)

TOTAL

$3,789,021$

164,740

\section{Income}

IRC/USAID (salary)

$1,582,036$

68,784

24,182

1,051

IRC

$1,639,671$

71,290

438,480

19,064

Mercy Fund

$3,684,369$

160,190

TOTAL

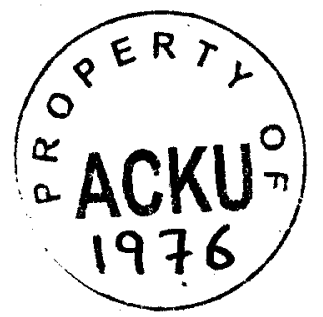




\section{Expenditure}

Medicine

Laboratory

Clinical Supply

Food

Utilities (Electricity,

Gas, Water, etc)

Vehicle Running Costs

(Gasoline, Repair, Trans)

Construction

Insurance (Staff, Vehicle,

House, Equipment)

Communication (Telephone,

Telegram, Postage)

Office Supply

Salary, Overtime, Bonus

Emergency Aid and Trips

Housing (house rent)

TOTAL

\section{Income}

IRC/USAID (salary)

Help

Help the Afghans Foundation

Australian Embassy

Norwegian Relief Committee/

Church Aid

Swedish Committee for Afghanistan

Norwegian Embassy

Refugees International (Japan)

$\begin{array}{rr}\text { Rupees } & \text { Dollars } \\ 1,189,425 & 51,714 \\ 321,547 & 13,908 \\ 297,483 & 12,934 \\ 341,952 & 14,867 \\ 257,712 & 11,205\end{array}$

283,253

12,315

97,887

4,256

68,905

2,995

74,348

3,233

42,725

$2,135,590$

1,858

654,327

92,852

28,449

$5,765,154$

250,658

2,138,239

708, 192

700,000

498,388

410,000

400,000

300,000

200,000

92,967

30,791

30,443

21,669

17,826

17,391

13,043

8,696

$\overline{5,354,819}$

232,818 


\section{Expenditure}

Medicine

+ Arrears

Laboratory

Clinical Supply

Food

Utilities (Electricity,

Gas, Water, etc)

Vehicle Running Costs

(Gasoline, Repair, Trans)

Construction

Insurance (Staff, Vehicle,

House, Fruipments

Communication (Telephone,

Telegram, Postage)

Office Supply

Salary, Overtime, Bonus

Emergency Aid and Trips

Housing (house rent)

TOTAL

Income

IRC/USAID (salary)

Help

Help the Afghans Foundation

Swedish Committee for Afghanistan

Norwegian Relief Committee/

Church Aid

Refugees International (Japan)

Australian Embassy

Norwegian Embassy

Commissioner for Afghan Refugees

APWA

TOTAL

\begin{tabular}{rr} 
Rupees & Dollars \\
$1,895,304$ & 82,405 \\
199,750 & 8,685 \\
384,903 & 16,735 \\
559,813 & 24,340 \\
401,326 & 17,449 \\
298,266 & 12,968 \\
& \\
597,198 & 25,965 \\
& \\
231,246 & 10,054 \\
80,436 & 3,497 \\
& \\
104,179 & 4,530 \\
& \\
90,082 & 3,917 \\
$2,844,749$ & 123,685 \\
200,335 & 8,710 \\
660,000 & 28,696 \\
\hline $8,547,589$ & 371,634
\end{tabular}

\begin{tabular}{rr}
$3,044,545$ & 132,371 \\
390,166 & 16,964 \\
300,000 & 13,043 \\
800,000 & 34,783 \\
& \\
$3,022,500$ & 131,413 \\
318,100 & 13,830 \\
329,477 & 14,325 \\
300,000 & 13,043 \\
250,000 & 10,870 \\
57,174 & 2,486 \\
\hline $8,811,962$ & 383,129
\end{tabular}

N.B. Any shortfall in income not covered by the income listed above has been met from private donations, largely from the United States.

Rupee to US Dollar conversion rate used throughout is 1 US $\$=$ Rs. 23 


\section{Funding}

As with most small Afghan NGO's our funding situation is at best adequate, at worst extremely precarious. Over the past three years several times we have had to obtain emergency donations to enable us to keep running. We are presently trying to make certain of funding for 1991 and to obtain funds for service developments, particularly the outreach programme and the midwife training course.

The International Rescue Committee, without whose backing the Afghan Obs and Gynae Hospital might never have come into existence, have continued to be among our most regular donors, although their contribution has reduced over recent years. USAID, who channel their aid through IRC, are now our most generous donors, providing $\$ 9,000$ a month towards our salary bill. Last year we also received donations from the Norwegian Relief Committee/Church Aid, the Swedish Committee, HELP of West Germany, Help the Afghans Foundation of the Netherlands and Refugees International of Japan, who we hope will continue to support our work in 1991. JCA of Japan donated the ultrasound and other high quality technical equipment to the hospital in 1989 - 1990. Private donations have continued to be an important source of revenue for us, and last year we also received donations from the Australian and Norwegian Embassies. Free Afghanistan Alliance donated two computers.

Since the Soviet troop withdrawal in 1989, the attention of the international community has shifted from Afghanistan to other areas of crisis around the world. The world view now seems to be that the Afghan people should quietly return home and allow themselves to be forgotten. Unfortunately, things are not that simple - the fighting in Afghanistan continues, refugees continue to arrive in Pakistan and the several million still remaining are as in need of assistance as ever. In addition, as hopes for large-scale repatriation grow, the need for aid in Afghanistan itself becomes of paramount importance. We at the Afghan Obs and Gynae Hospital feel that we still have a very important task to accomplish, our patient numbers continue to grow, we continue to train more and more staff who will take their skills back to Afghanistan and we are looking forward to our own future in our homeland. We would therefore urge our friends all over the world not to forget the 'Afghan problem' - it still exists, and we are perhaps more in need of your support than ever before. 


\section{Acknowledorments}

The Afghan Obs and Gynae Hospital would like to take this opportunity to express its gratitude and appreciation to the people and government of Pakistan for welcoming and sheltering their Afghan neighbours in their time of need. The refugee population in the west of Pakistan has now continued to grow over 12 years, and without their continued interest and support our life would be much more difficult than it is at present.

We would like to thank all our generous donors, without whose continued support our work among the neglected Afghan women would not have been able to continue and to develop. Very special thanks are extended to IRC who have supported us from the outset and remained loyal friends of the Afghan Obs and Gynae Hospital ever since. We would also like to thank the following:

The Commissioner for Afghan Refugees, Peshawar

Free Afghanistan Allią̧ce - United States

Help - West Germany

Help the Afghans Foundation - the Netherlands

Japanese International Co-operation for Assistance

Norwegian Refugee Council/Norwegian Church Aid - Norway

Refugees international Japan

Swedish Committee for Afghanistan - Sweden

USAID - United States

H. E. Jeffery Price, High Commissioner of Australia and H. E. Jan Naerby, Ambassador of Norway.

and all the friends who have given financial and moral support over the past three years.

We would also like to thank Dr. Qudratullah Mojadidi, Chairman of the Board of Directors for his continued support, both moral and practical, since the hospital was first conceived. We would like to express our gratitude to all those health professionals from the West who have given us the benefit of their expertise so generously over the years. They are far too numerous to mention but special thanks must go to Dr. William Hazlett who has worked completely voluntarily on 24 hour call for 3 years now and without whom we would have been unable to operate on and save the lives of many women and babies, and to Dr. Jack Turner who has made extended visits to the hospital on several occasions, working alongside our medical staff and teaching them the latest medical techniques from the United States.

Last but not least our thanks go to all our staff, some of whom have been with the hospital since we first opened our doors in 1984, without them none of our achievements would have been possible. 


\section{Activity \\ 1987 - 1990}

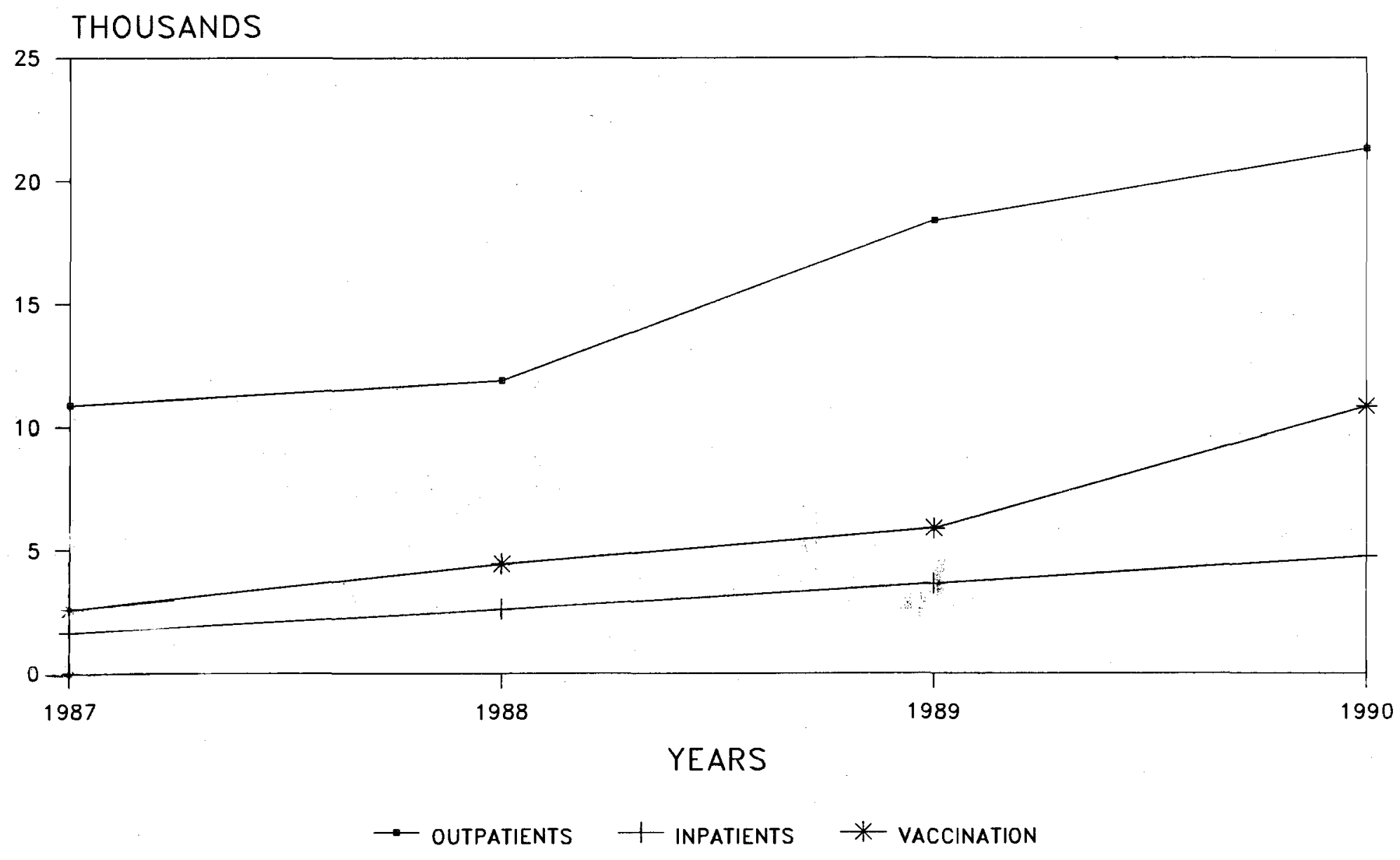




\section{Outpatients 1988 - 1990}

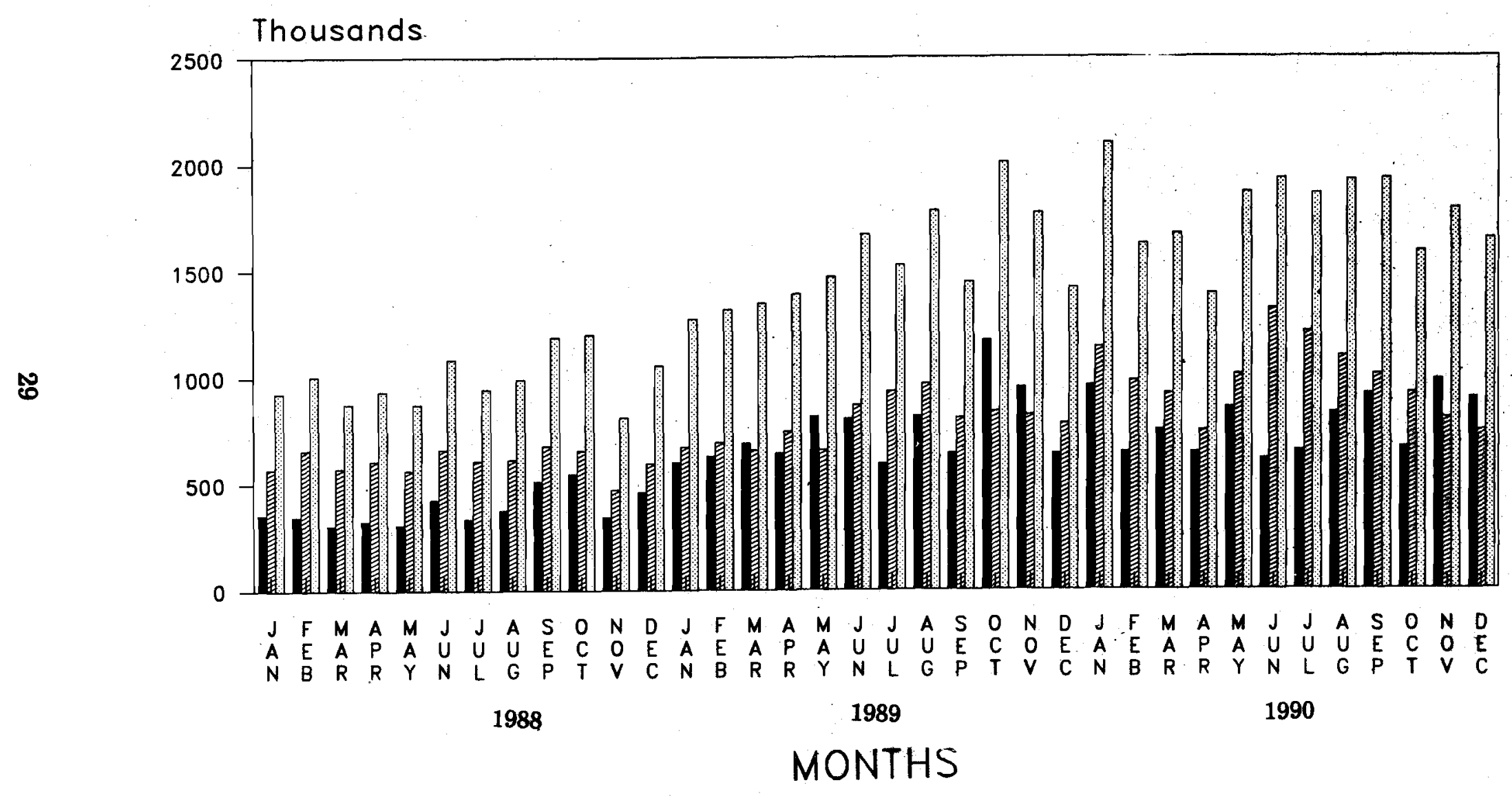

nEW ${ }_{\text {NE OLD }}$ TOTAL 


\section{Outpatients by Type 1988}

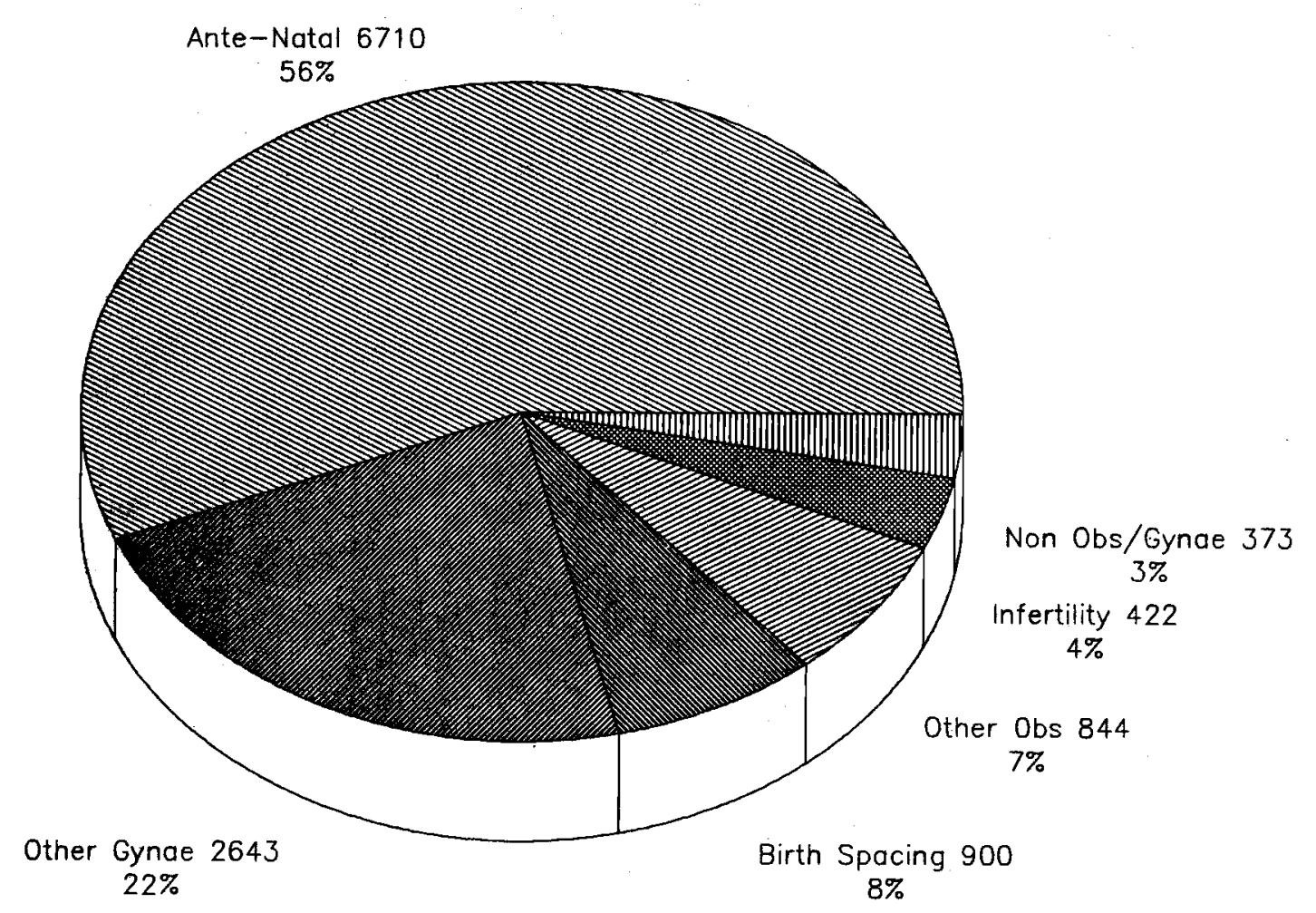




\section{Outpatients by Type 1989}

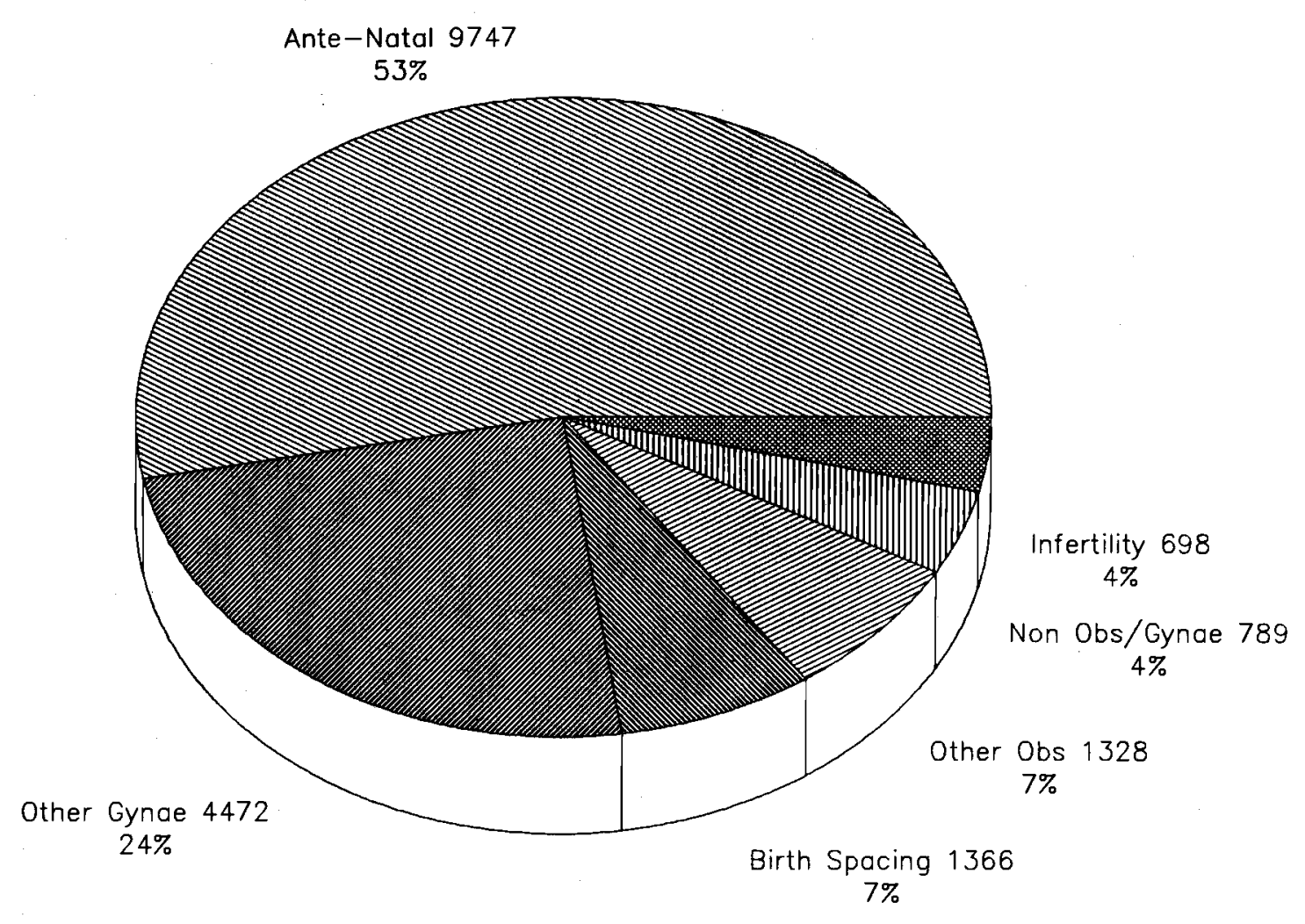




\section{Outpatients by Type 1990}

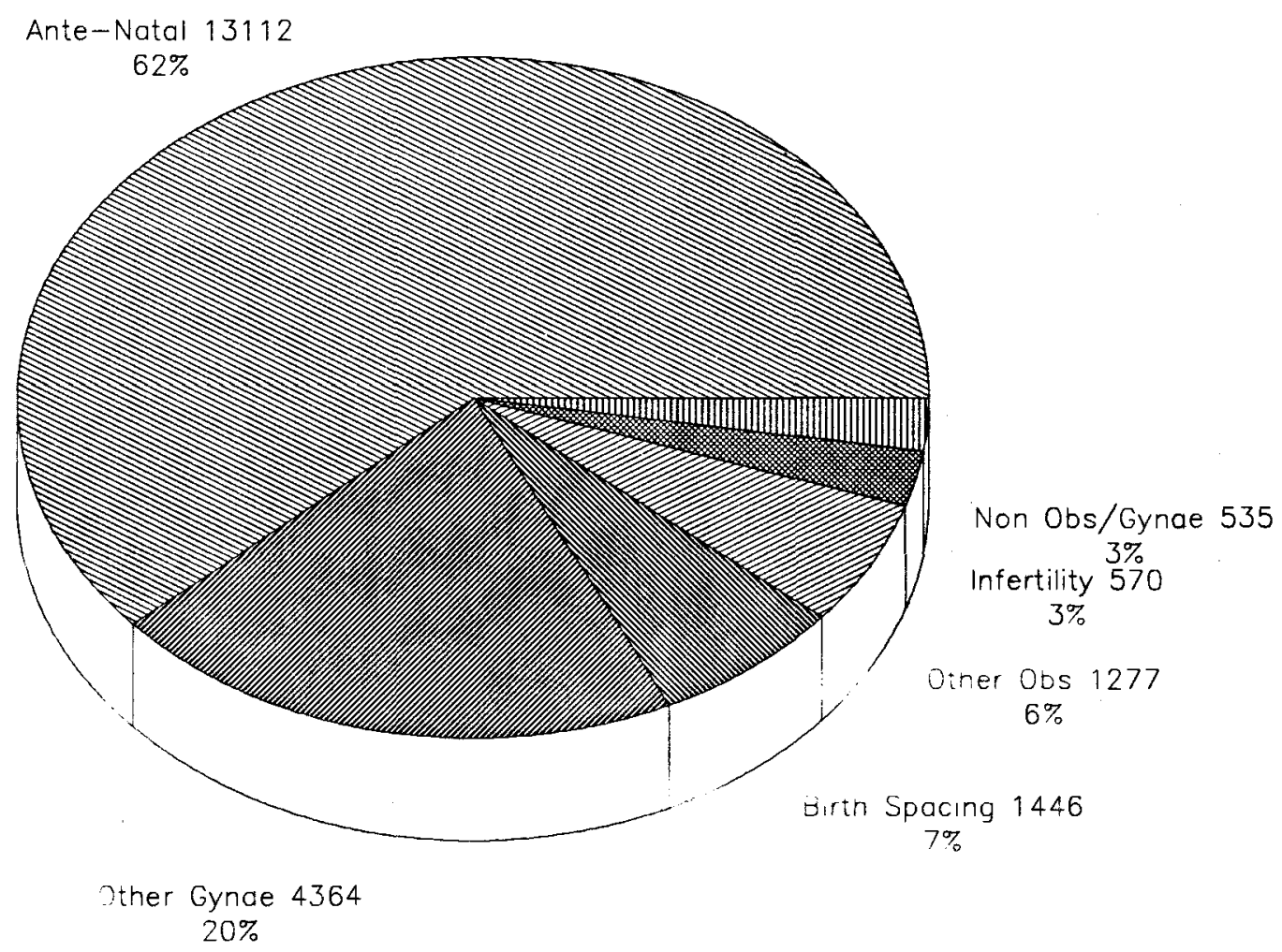




\section{Vaccinations 1988 - 1990}

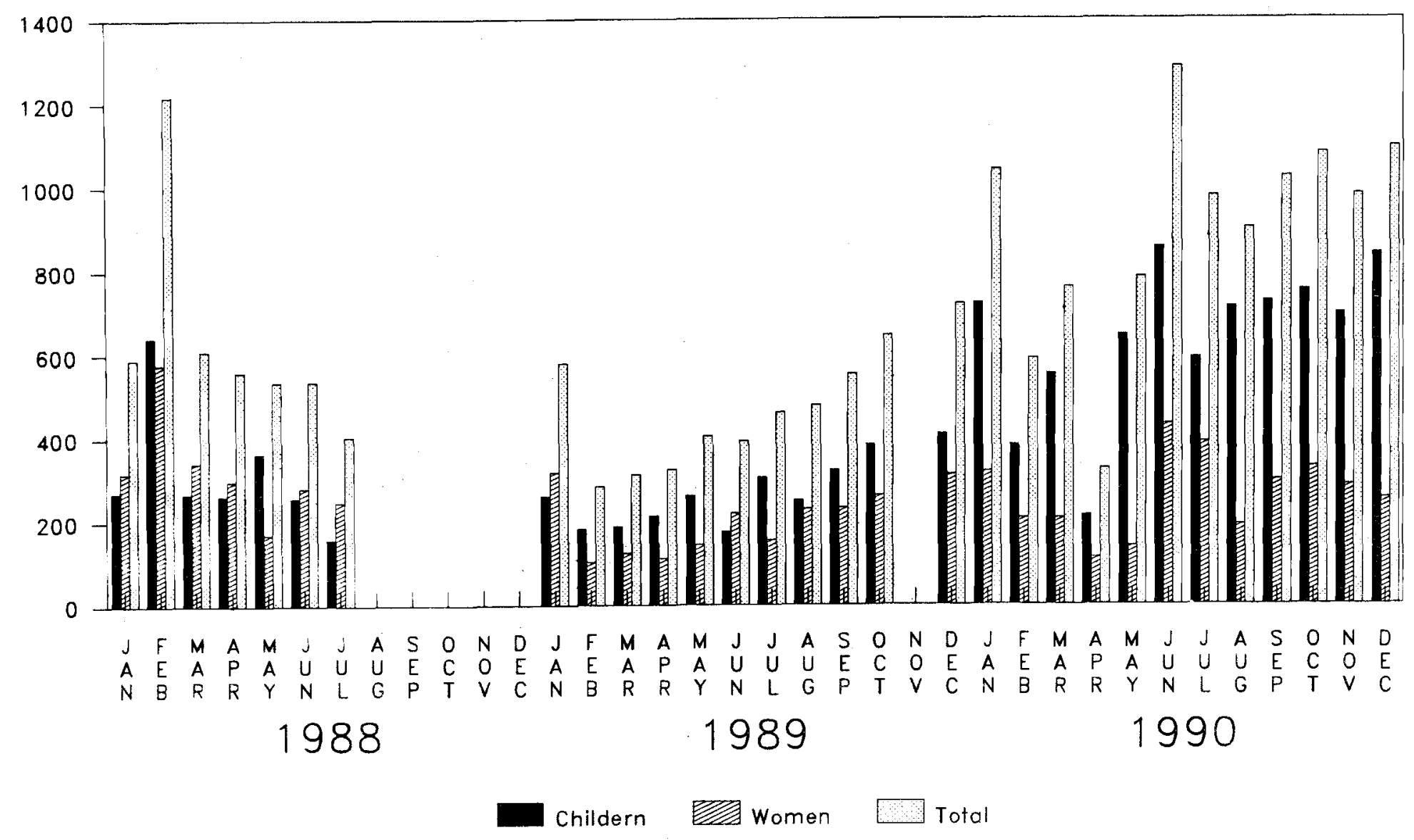




\section{In - Service \\ 1988 - 1990}
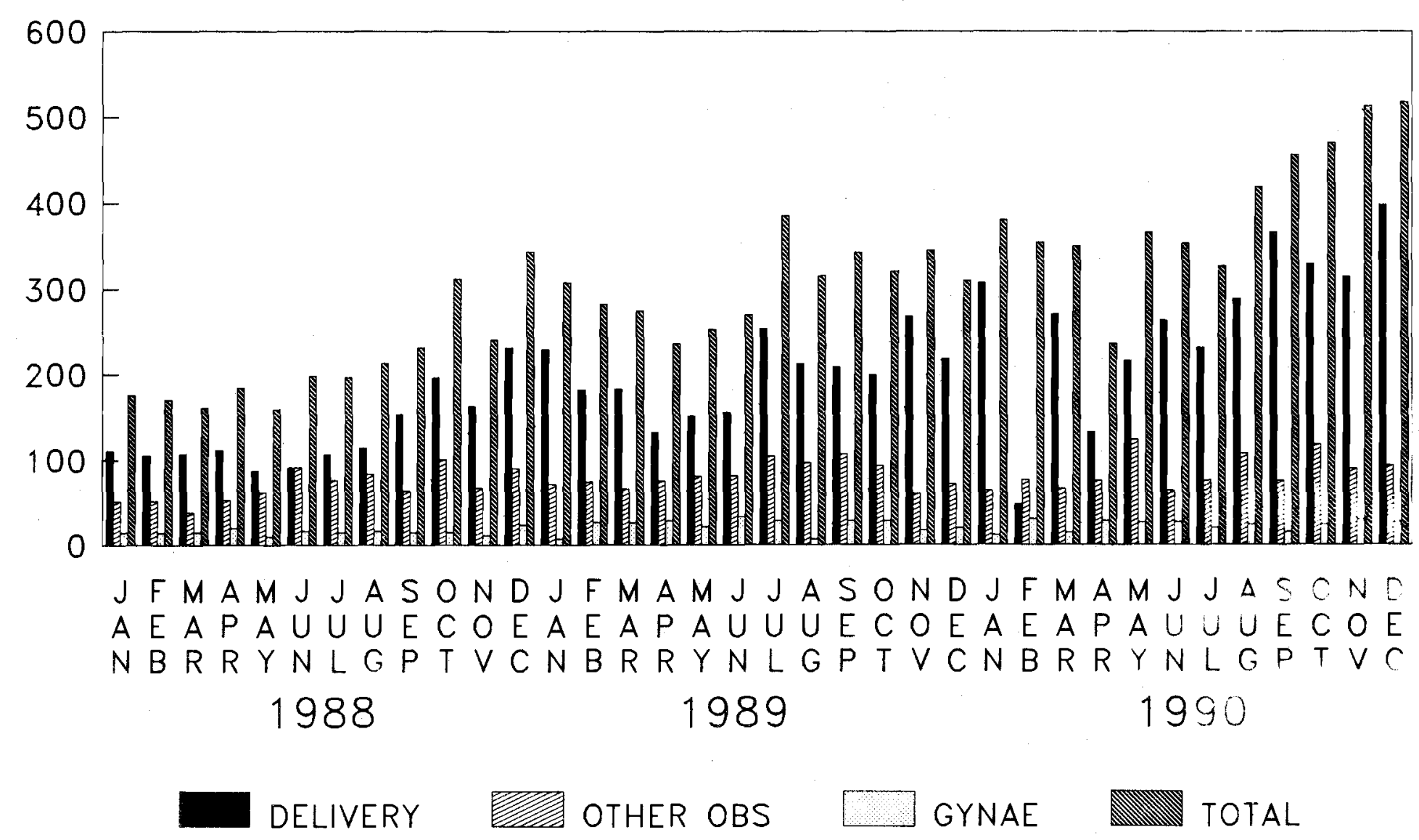


\section{Surgery \\ $1988-1990$}

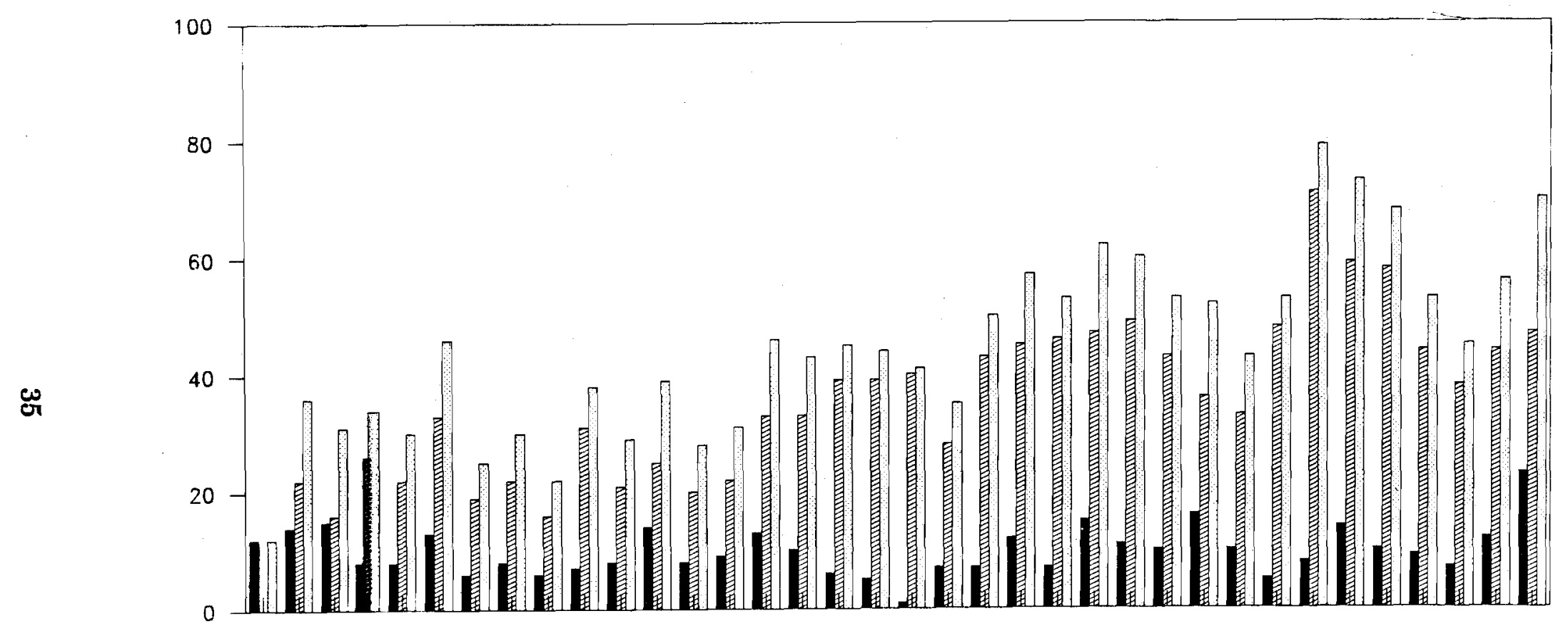

J F M A M J J A S S O $N$ N D J J F M A M J J A $\begin{array}{llllllllllllllllllllllllllllllllllll}A & E & A & \mathbf{P} & A & U & U & U & E & C & O & E & A & E & A & P & A & U & U & U & E & C & O & E & A & E & A & P & A & U & U & U & E & C & O & E \\ N & B & R & & Y & N & L & G & P & T & V & C & N & B & R & R & Y & N & L & G & P & T & V & C & N & B & R & R & Y & N & L & G & P & T & V & C\end{array}$ 1988 1989 1990

Mijor Minor $\square$ Total 


\section{Major Surgery by Type 1988}

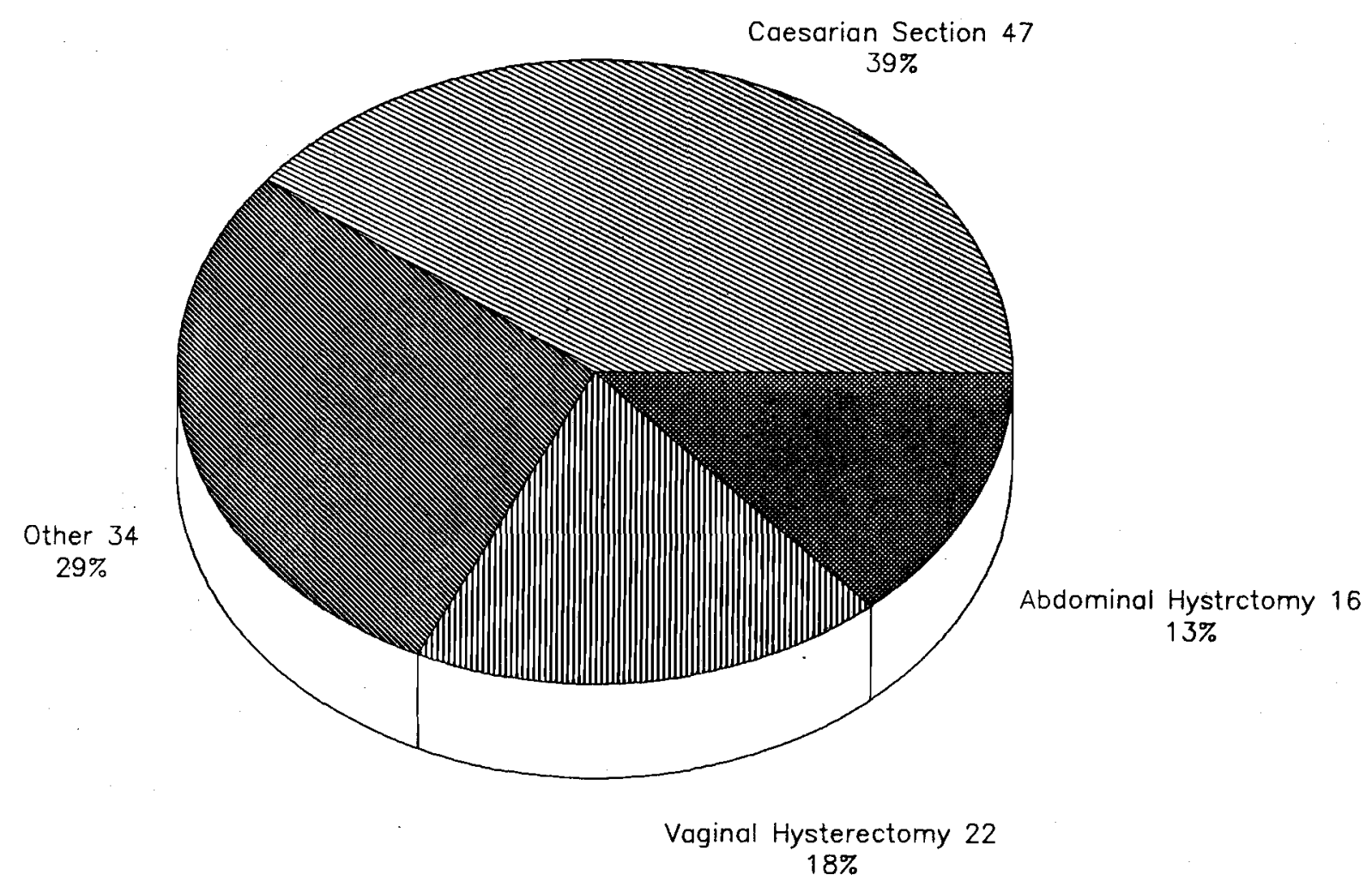




\section{Major Surgery by Type 1989}

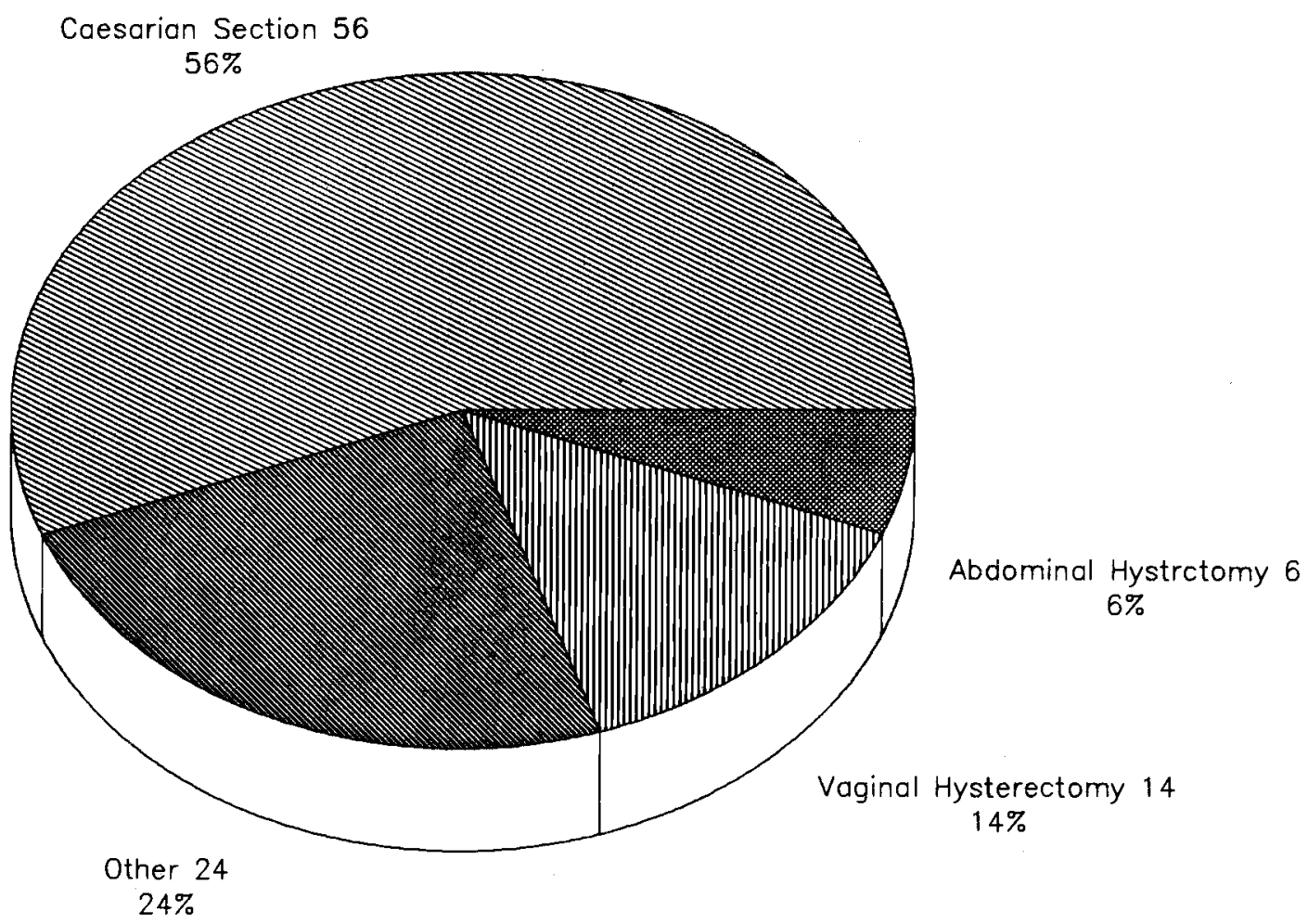




\section{Major Surgery by Type 1990}

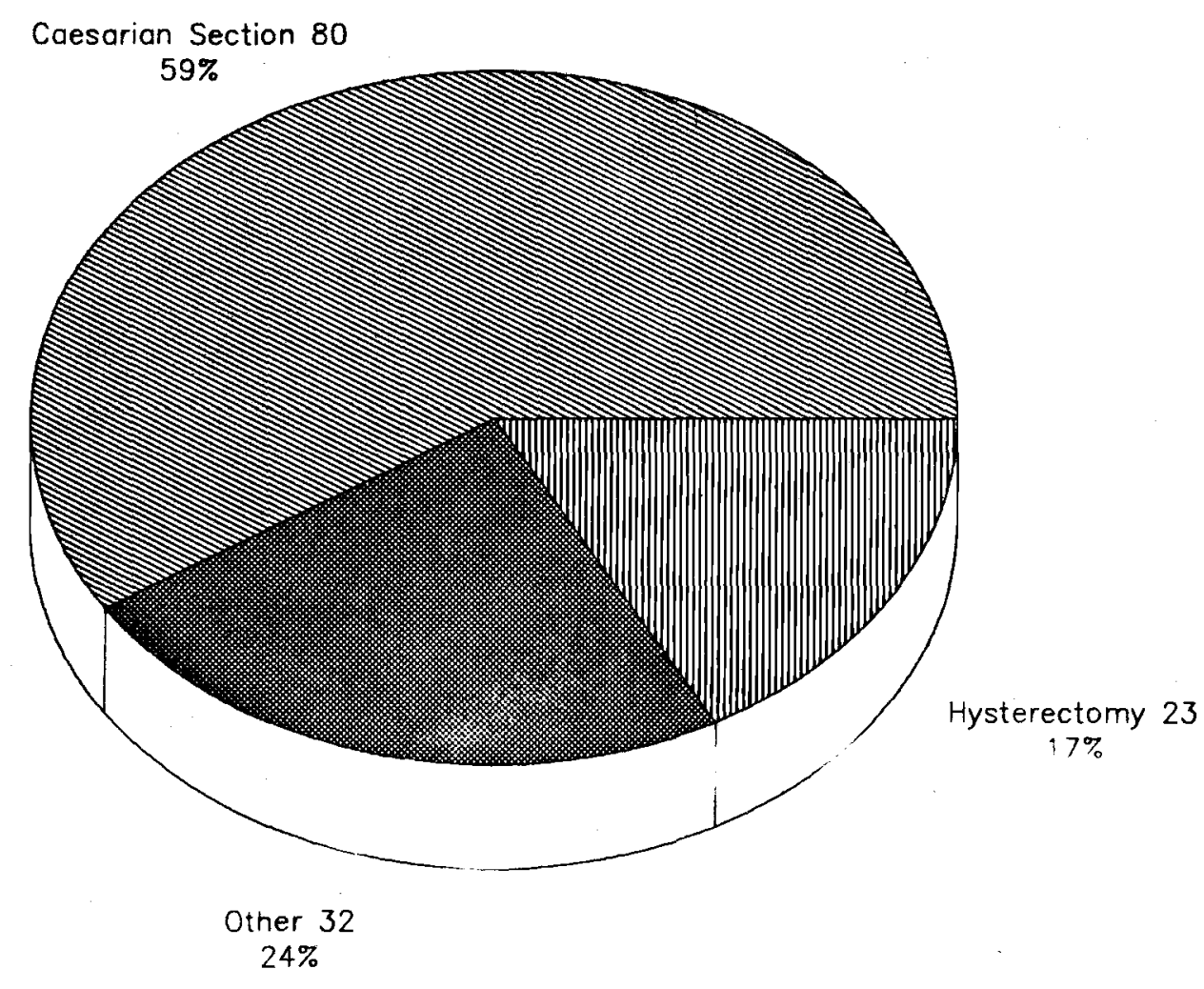




\section{Minor Surgery by Type 1988}

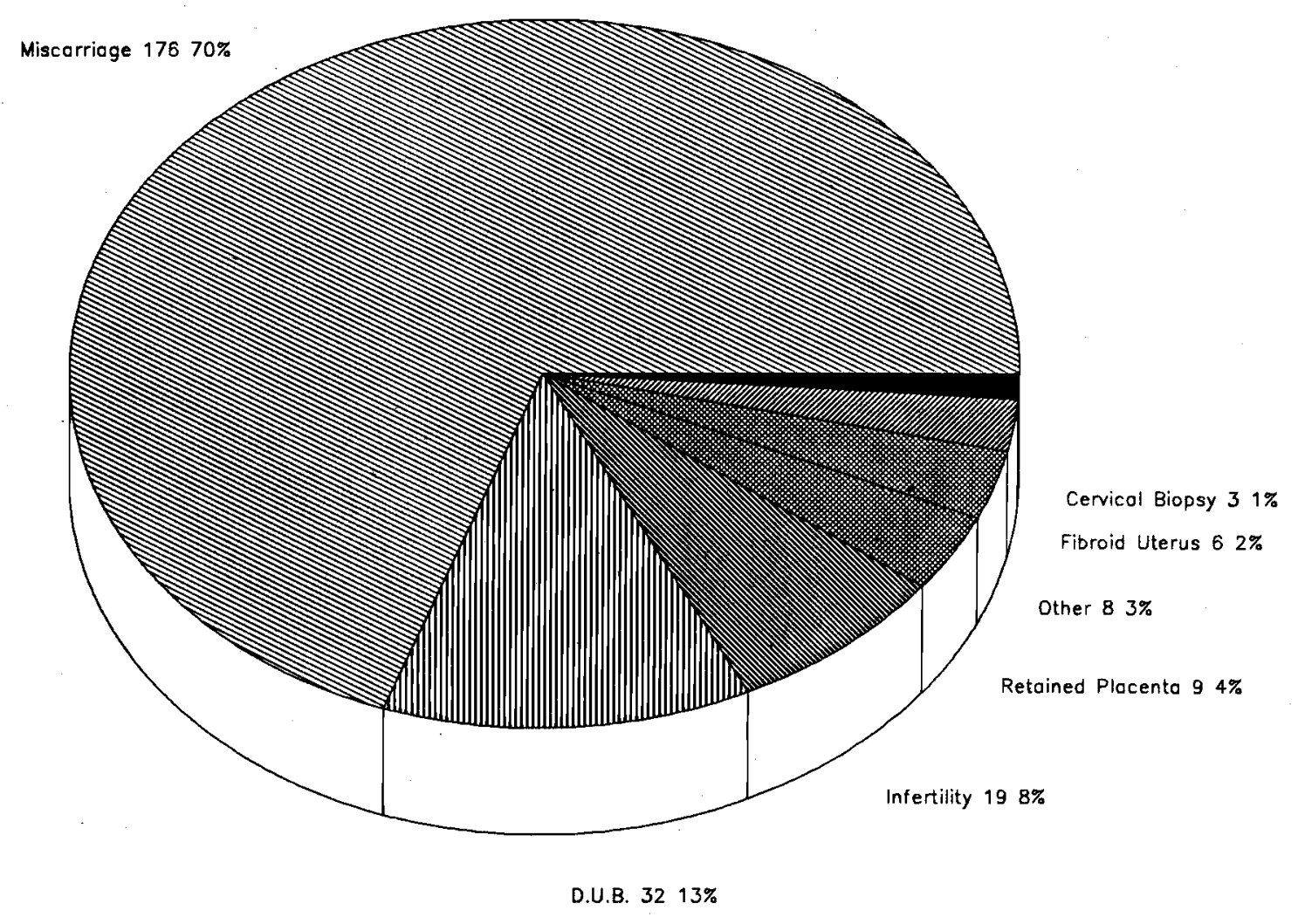




\section{Minor Surgery by Type}

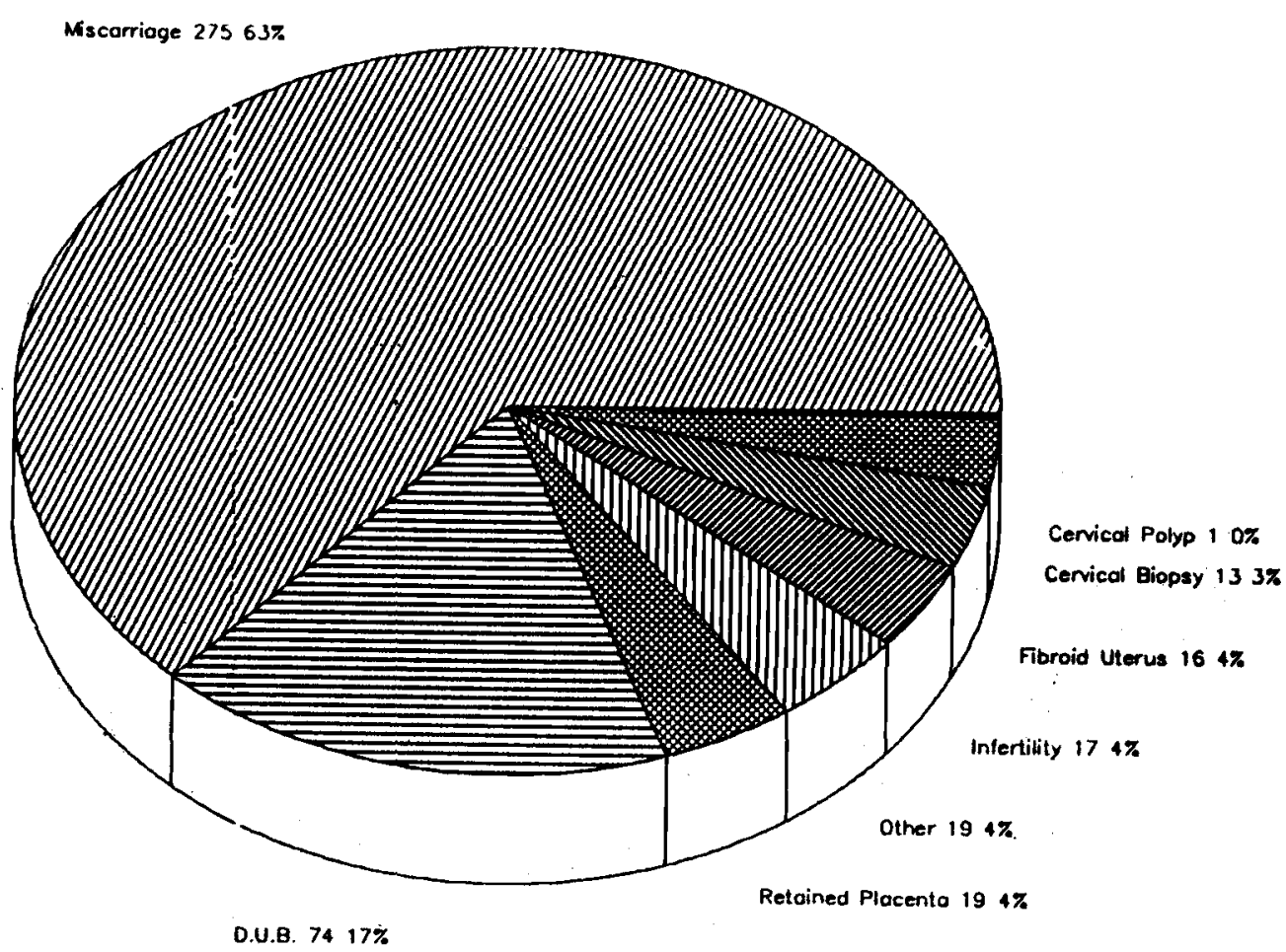




\section{Minor Surgery by Type 1990}

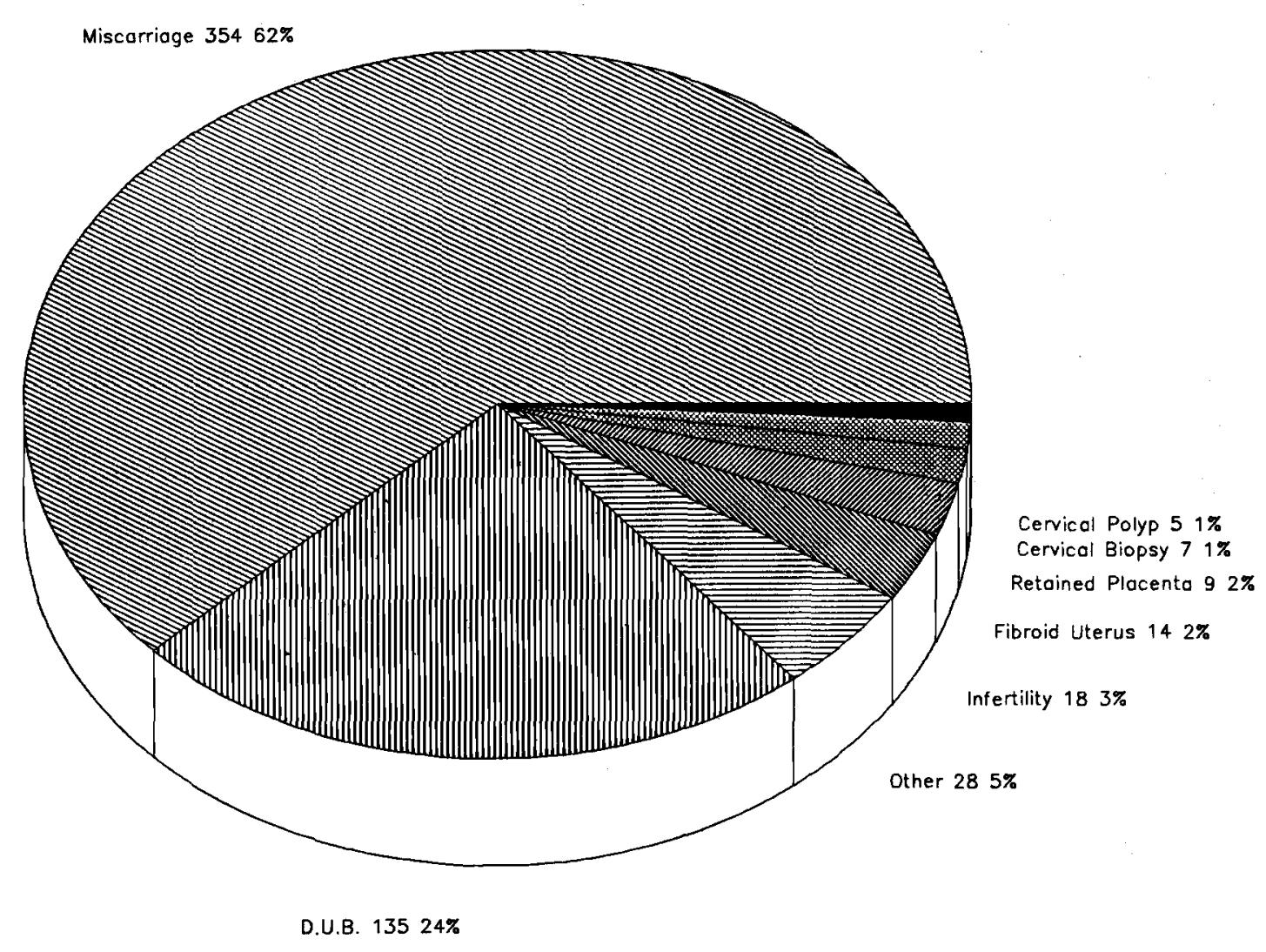

